\title{
Presynaptic Influence on the Time Course of Fast Excitatory Synaptic Currents in Cultured Hippocampal Cells
}

\author{
Steven Mennerick' and Charles F. Zorumski² \\ 'Program in Neuroscience and 'Departments of Psychiatry, and Anatomy and Neurobiology, Washington University \\ School of Medicine, St. Louis, Missouri 63110
}

\begin{abstract}
Since the lifetime of synaptically released glutamate is thought to be very brief, reflecting diffusion and glutamate uptake, the decay of synaptic currents is thought to represent the average elementary lifetime of a receptor channel bound only once by transmitter molecules. We show here that the decay of evoked non-NMDA synaptic currents can reflect presynaptic factors, in particular, the prolonged action of transmitter at postsynaptic receptors under conditions of enhanced transmitter release. We show that diffusion, high-affinity glutamate uptake, and non-NMDA receptor desensitization are insufficiently rapid to limit the decays of evoked synaptic currents to those of miniature synaptic currents in microcultures of rat hippocampal cells. Our results are consistent with recent studies suggesting that during evoked release, multiple glutamate quanta can interact with overlapping postsynaptic receptor domains.
\end{abstract}

[Key words: glutamate uptake, non-NMDA, synaptic transmission, microcultures, EPSC, desensitization]

It is important to understand the factors contributing to the time course of synaptic currents, since the rate of synaptic current decay is likely to influence information processing in the CNS. $\Lambda t$ the vertebrate neuromuscular junction (NMJ), individual quanta of acetylcholine are rapidly hydrolyzed by acetylcholinesterase following synaptic release so that quantal synaptic currents are normally dictated by the elementary lifetime of activated postsynaptic receptor channels rather than by rebinding of transmitter to receptors (Anderson and Stevens, 1973). Acetylcholinesterase also normally serves to isolate individual quanta of transmilter during evoked release so that interaction between acetylcholine released by adjacent synaptic sites (spill over) is normally prevented (Hartzell et al., 1975). Therefore, presynaptic influences upon the decay of evoked postsynaptic currents are minimal, and evoked synaptic currents of large quantal content decay with a similar time course to quantal synaptic currents (Kordas, 1972; Magleby and Stevens, 1972; Anderson and Stevens, 1973; Hartzell et al., 1975).

\footnotetext{
Received Aug. 9, 1994, revised Oct. 10, 1994; accepted Nov. 9, 1994.

This work was supported by NIMH research scientist development award MH00964, Grant MH45493, and a fellowship from the Bantly Foundation. We thank Ann Benz and Jian Que for technical assistance and Jim Huettner, Bob Wilkinson, Steve Rothman, Joe Henry Steinbach, Yuki Izumi, David Clifford, and Liu Lin Thio for valuable discussions. We also thank Gang Tong and Craig Jahr for sharing unpublished results.

Correspondence should be addressed to Dr. Charles F. Zorumski, Department of Psychiatry, Washington University School of Medicine, 4940 Children's Place, St. Louis, MO 63110.

Copyright $(\mathcal{C} 1995$ Society for Neuroscience $0270-6474 / 95 / 153178-15 \$ 05.00 / 0$
}

At vertebrate CNS glutamatergic synapses, rapid diffusion (Eccles and Jaeger, 1958) and high-affinity glutamate uptake (Curtis et al., 1970; Mennerick and Zorumski, 1994) are thought to limit the concentration of glutamate in the synaptic cleft to an extremely brief transient (Lester et al., 1990; Clements et al., 1992). These considerations have focused attention primarily upon postsynaptic determinants of decay time course of fast excitatory postsynaptic currents (EPSCs). While some evidence suggests that the closing rate of non-NMDA receptor channels is a primary determinant of the decay of fast non-NMDA receptor-mediated EPSCs (Colquhoun et al., 1992; Hestrin, 1992, 1993), it is also possible that non-NMDA receptor desensitization is sufficiently fast to play a role in non-NMDA EPSC decays (Trussell and Fischbach, 1989; Isaacson and Nicoll, 1991; Vyklicky et al., 1991; Thio et al., 1992; Trussell et al., 1993). Little attention has been given to possible presynaptic influences upon non-NMDA EPSC decays, although recent evidence from hippocampal microcultures (Tong and Jahr, 1994) suggests that effective glutamate concentrations can last longer under conditions where the probability of evoked transmitter release is high. However, the physiological implications of such findings are unclear. In particular, it is unclear whether changes in glutamate concentration transients are sufficient to alter the EPSC time coursc.

In this work, we characterize both evoked and miniature nonNMDA EPSCs of postnatal rat hippocampal cells in a microisland environment convenient for the study of synaptic transmission between CNS neurons (Bekkers and Stevens, 1991; Segal, 1991). We show that decays of evoked non-NMDA EPSCs at microisland synapses can reflect prolonged actions of glutamate even when glutamate uptake and fast receptor desensitization are intact.

\section{Materials and Methods}

Cultures. Microisland cultures were prepared as previously described (Mennerick and Zorumski, 1994; Mennerick et al. 1994). Briefly, hippocampal slices $500-800 \mu \mathrm{m}$ thick were prepared from $1-3 \mathrm{~d}$ postnatal Sprague-Dawley rats and treated with $1 \mathrm{mg} / \mathrm{ml}$ papain in oxygenated Leibovitz's L-15 medium. After transfer to Eagle's MEM containing $5 \%$ horse serum, $5 \%$ fetal calf serum, $17 \mathrm{~mm}$ D-glucose, $400 \mu \mathrm{M}$ glutamine, $50 \mathrm{U} / \mathrm{ml}$ penicillin, and $50 \mu \mathrm{g} / \mathrm{ml}$ streptomycin, slices were gently triturated by passage through Pasteur pipettes of decreasing diameter until a single cell suspension of approximately 20,000 cells per $\mathrm{ml}$ was obtained. Plastic culture dishes $(35 \mathrm{~mm}$ diameter) had been previously coated with $0.15 \%$ agarose, dried overnight, then sprayed with collagen $(0.5 \mathrm{mg} / \mathrm{ml} \mathrm{rat} \mathrm{tail,} \mathrm{Sigma} \mathrm{Type} \mathrm{I)} \mathrm{droplets} \mathrm{using} \mathrm{a} \mathrm{mi-}$ croatonizer (Thomas Scientific). After $3 \mathrm{~d}$ in culture, all cells were treated with $10 \mu \mathrm{M}$ cytosine arabinoside to halt glial proliferation. Cells were used for experiments $8-16 \mathrm{~d}$ following plating.

Solutions and drugs. The extracellular recording solutions consisted (in $\mathrm{mM}$ ) of $138 \mathrm{NaCl}, 4 \mathrm{KCl}, 10$ HEPES, 10 glucose. Divalent cation 
concentrations were manipulated in various experiments as indicated in the figure legends and text. Osmolarity was maintained at $310 \mathrm{mOsm}$ by addition of sucrose, and $\mathrm{pH}$ was adjusted to 7.25 with $\mathrm{NaOH}$. Unless otherwise specified, D-amino-5-phosphonovaleric acid (D-APV) was present at $30-50 \mu \mathrm{M}$ to block contributions of NMDA receptors to synaptic currents. These concentrations were found in pilot studies to block NMDA contributions completely under the conditions of these experiments. In experiments in which solution changes were made, cells were continuously perfused at a rate of $0.1 \mathrm{ml} / \mathrm{min}$ with baseline or drug-containing solutions using a multibarrel local perfusion system. Complete solution exchanges could be obtained in $750 \mathrm{msec}$.

Pipette solutions used for stimulating presynaptic cells, for eliciting autaptic responses, and for glial cell recordings usually contained (in mM) 140 potassium gluconate, $4 \mathrm{NaCl}, 5$ EGTA, 2 MgATP, 10 HEPES, $\mathrm{pH} 7.25$ with KOH. In some of the experiments of Figure 1, a Nystatin perforated patch technique was used to stimulate presynaptic cells and to elicit evoked autaptic currents. This solution contained (in mM) 125 potassium gluconate, $10 \mathrm{KCl}, 5 \mathrm{NaCl}, 3 \mathrm{MgCl}_{2}, 10$ HEPES, pH 7.25. Nystatin, Pluronic F127, and DMSO were present at $300 \mu \mathrm{g} / \mathrm{ml}, 250$ $\mu \mathrm{g} / \mathrm{ml}$, and $0.35 \%$, respectively. No systematic differences in responses elicited with this solution versus the standard whole-cell solution were noted, so results were pooled. Pipette solutions used for recording EPSCs or mEPSCs usually consisted of (in mM) 140 cesium methanesulfonate, $5 \mathrm{NaCl}, 5 \mathrm{BAPTA}, 2 \mathrm{MgATP}, 10 \mathrm{HEPES}$, with $\mathrm{pH}$ adjusted to 7.25 with $\mathrm{CsOH}$.

All chemicals and drugs for experiments were from Sigma (St. Louis, MO) except D-APV (Cambridge Research Biochemicals, Wilmington, DE), NBQX (2,3-dihydroxy-6-nitro-7-sulphamoylbenzo(F)quinoxaline, generous gift of John Olney, Washington University), 6-cyano-7-nitroquinoxaline-2,3-dione (CNQX; Cambridge), cyclothiazide (CY' $L$; gift of Lily Pharmaceuticals, Indianapolis, IN), (-)baclofen (gift of CIBAGEIGY, Summit, NJ), Pluronic F127 (Molecular Probes, Eugene, OR). CNQX, NBQX, GYKI 52466, and CYZ were stored as concentrated stock solutions in dimethylsalfoxide. All solutions in experiments employing these drugs were routinely matched for final dimethylsulfoxide concentration, which was usually below $0.15 \%$.

Synaptic current recordings. Cells selected for study usually had large, rounded phase-bright somata typical of excitatory ncurons in microcultures (Bekkers and Stevens, 1991; Segal, 1991). Except for experiments in Figure 3, autaptic currents were evoked using a discontinuous single electrode voltage clamp (Axoclamp 2 A amplifier, 8-11 $\mathrm{kHz}$ switching frequency). Presynaptic cells were stimulated using the same amplifier in either the discontinuous single electrode voltageclamp or discontinuous current-clamp modes. Stimulation of cells was achieved in the voltage-clamp mode with a $1.5 \mathrm{msec}$ voltage step to $+20 \mathrm{mV}$ (from a holding potential between -50 and $-70 \mathrm{mV}$ ) or in the current-clamp mode with a $1.5 \mathrm{msec}$ depolarizing current step usually of 1-2 nA. Postsynaptic EPSCs and mEPSCs were recorded using an Axopatch 1-D amplifier. Series resistance (5-10 M $\Omega$ ) was compensated $80-90 \%$. Currents were filtered at $2 \mathrm{kHz}$ and stored at $3-5 \mathrm{kHz}$. Unless otherwise noted, currents displayed in figures represent average waveforms of 2-300 responses. Evoked currents are usually the average of 3-10 responses. All experiments were performed at room temperature $\left(20-25^{\circ} \mathrm{C}\right)$.

Analysis. During experiments, evoked responses were collected to computer disk and mEPSCs and sEACs were collected to VCR tape for off-line analysis as previously described (Mennerick et al., 1994). Analysis of currents was performed using averaging and analysis programs written in AXOBASIC (Axon Instruments, Foster City, CA), except for exponential fits of current decays, which were performed using a commercially available iterative fitting routine (pCLAMP 5.51, Axon Instruments). Fits of the decays of currents were performed on averaged waveforms from $5-10 \%$ of the peak amplitude to $50-200 \mathrm{msec}$ following the peak and were extrapolated to the onset of synaptic currents for estimation of relative amplitudes of multiexponential components. To verify that $\mathrm{MEPSC}$ decays were significantly better described by the sum of two exponentials than by a single exponential, an $F$ test (Ellis and Duggleby, 1978) was performed on the averaged mEPSCs from each of the 13 cells analyzed. For several experiments (see Figs. 1, 5), decays of EPSCs and EACs were described with the sum of two exponentials in order to provide the most complete description of the currents decays. In the rest of the experiments, to simplify comparisons among experimental conditions and because not all currents could be fitted with the bi-exponential iterative fitting algorithm, the best single exponential fit was used as a description of the current decay.

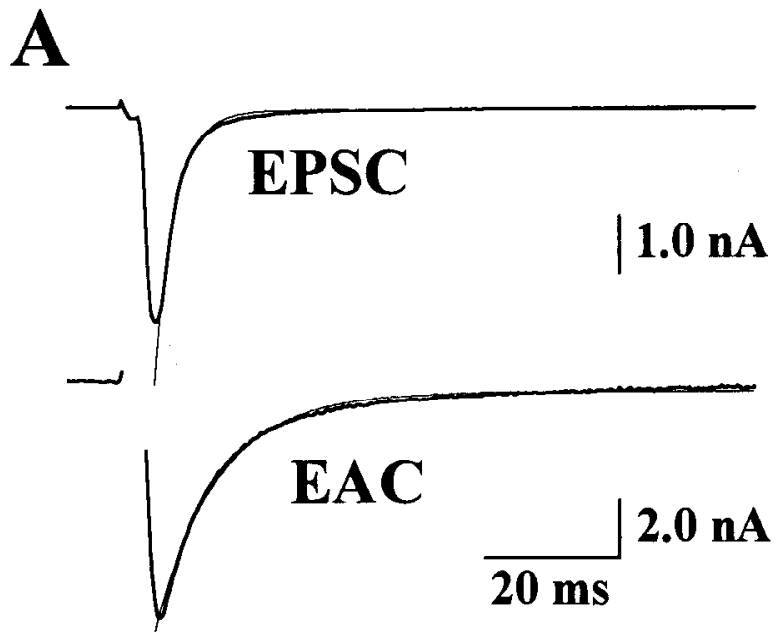

B

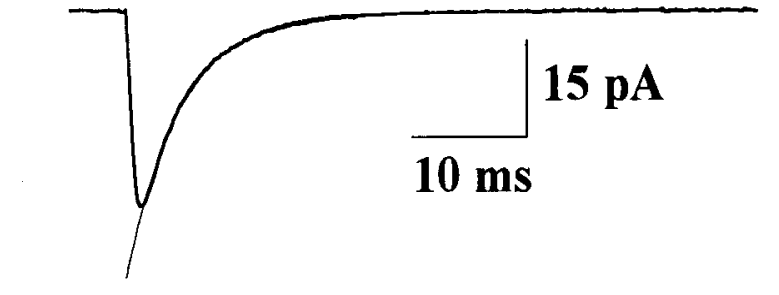

C1

C2
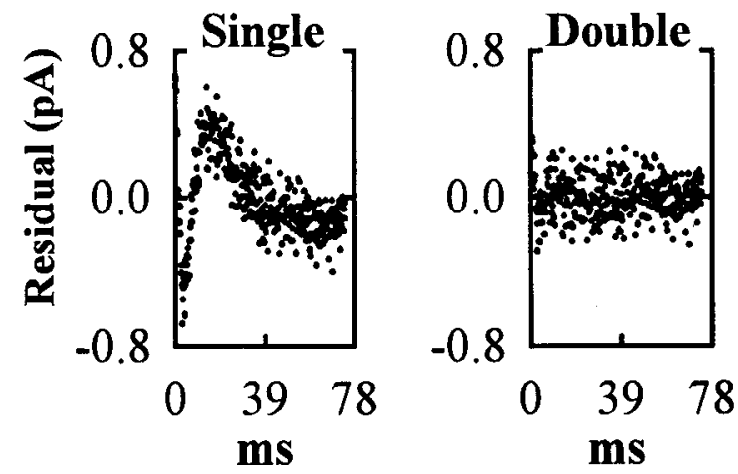

Figure 1. Decay time course of EPSCs, EACs, and mEPSCs. A, The traces show an example of averaged EPSCs (top) and EACs (bottom) from a two-neuron microisland. The optimal single exponential fit of each decay (thin lines), extrapolated to the onset of the current, is superimposed upon each current. For this pair, the $\tau$ values of the optimal fits were 3.1 (EPSC) and $9.3 \mathrm{msec}(E A C)$, although in both cases, the decays were better fitted by the sum of two exponentials (see Results). Stimulus-associated transients in the presynaptic trace have been blanked for clarity. $B$, The trace shows the average of 278 isolated mEPSCs obtained from a single-neuron microisland and aligned at the onset of the currents. Superimposed is the optimal single-exponential fit of the decay of the current. $C 1$ and $C 2$, The graphs show the residual current obtained from subtracting the optimal single exponential $(C l)$ or bi-exponential $(C 2)$ fit from the actual decay of the waveform shown in $B$. The nonrandom pattern in the residuals of the single exponential fit suggests that a single exponential model is insufficient to describe the decay phase of mEPSCs. Optimal fit parameters for the cell represented in $B$ and $C$ were $\tau=4.7 \mathrm{msec}$ (single exponential fit), $\tau_{\mathrm{f}}=3.5$ msec, $\tau_{\mathrm{s}}=8.5 \mathrm{msec}$, and $A_{\mathrm{f}}=77 \%$. The divalent cation concentration was $2 \mathrm{~mm} \mathrm{Ca}{ }^{2+}, 1 \mathrm{mM} \mathrm{Mg}^{2+}$. 


\section{Results}

We analyzed 14 smoothly decaying evoked excitatory synaptic currents (EPSCs) from two-neuron microislands and 100 excitatory autaptic currents (EACs) from single-neuron microislands in cultures maintained $8-12 \mathrm{~d}$ in vitro and recorded in solutions containing $2 \mathrm{mM} \mathrm{Ca}{ }^{2+}$ and $1 \mathrm{mM} \mathrm{Mg}^{2+}$. While many EPSC and EAC decays were reasonably well fitted by a single exponential (Fig. 1A), most showed a distinctly better fit using the sum of two exponentials. For EPSCs, optimal single exponential fits exhibited an average $\tau$ of $4.8 \pm 0.5 \mathrm{msec}$ (range $1.5-8.5 \mathrm{msec}$ ) and EACs averaged $5.7 \pm 0.1 \mathrm{msec}$ (range $3.1-10.7 \mathrm{msec}$ ). In this data set, 13/14 EPSCs and 84/100 EACs could be described by the sum of two exponentials using the iterative algorithm employed. Bi-exponential fits of these currents revealed a fast component of decay with a time constant $\left(\tau_{f}\right)$ of $3.7 \pm 0.4 \mathrm{msec}$ (EPSCs) and $4.8 \pm 0.14 \mathrm{msec}$ (EACs). The slower component $\left(\tau_{\mathrm{s}}\right)$ averaged $24.8 \pm 5.4 \mathrm{msec}(\mathrm{EPSCs})$ and $28.8 \pm 9.4 \mathrm{msec}$ (EACs). The amplitude of the fast component $\left(A_{\mathrm{f}}\right)$ represented the majority of the total amplitude $(94 \pm 1 \%$, EPSCs; $93 \pm$ $1 \%$, EACs). The slow component of decay was not mediated by NMDA receptors since extracellular solutions contained both $\mathrm{Mg}^{2+}$ and D-APV and were nominally glycine free to block NMDA receptor-mediated synaptic responses.

Averaged miniature excitatory synaptic currents (mEPSCs, $n$ $=13$ cells, including the 8 cells used for Fig. 5), recorded in the presence of tetrodotoxin (TTX, $1 \mu \mathrm{M}$ ), also typically exhibited decays better described by the sum of two exponentials than by a single exponential as assessed by inspection of residual plots (Fig. $1 B, C$ ) and by a statistical $F$ test $(p<0.001$ for each of the 13 cells analyzed). For bi-exponential fits, parameters of mEPSC fits werc $\tau_{\mathrm{f}}=2.3 \pm 0.2 \mathrm{msec}, \tau_{\mathrm{s}}=7.4 \pm 0.8 \mathrm{mscc}$, and $A_{\mathrm{f}}=81 \pm 4 \%$ of the total amplitude. The best single exponential fit of the decay of mEPSCs as described with $\tau=3.2$ $\pm 0.3 \mathrm{msec}$ (range $1.4-4.8 \mathrm{msec}$ ).

Although decays of EACs, EPSCs, and mEPSCs were similar, the large EACs $(-6121 \pm 489 \mathrm{pA}, n=100)$ from single-neuron microislands showed a significantly slower decay $(p<0.03)$ than the smaller EPSCs in this sample $(-1677 \pm 409 \mathrm{pA}, n=$ 14). Slower EAC decays were not caused by the stimulus artifact preceding the autaptic currents, since decays of EACs from five cells with stimulus artifacts intact were nearly identical to decays of the same EACs after digitally subtracting the stimulus artifact (obtained by stimulating the cells in the presence of $10 \mu \mathrm{M}$ CNQX to block the non-NMDA EAC). The difference between the subtracted and the unsubtracted EAC decays was $-0.3 \pm$ $0.4 \%$.

EPSCs decayed slower, and decay rates were more variable than those of mEPSCs. While some of these effects could be due to differences in the adequacy of membrane voltage control during evoked currents of large and small quantal contents, or to asynchrony in evoked release of glutamate, another possibility is that the variability in decay rates reflects variability in the transmitter lifetime at these synapses. The experiments described below were designed to address this possibility.

Although evoked synaptic currents at the NMJ decay at nearly the same rate as miniature synaptic currents (Magleby and Stevens, 1972; Anderson and Stevens, 1973), cholinesterase poisoning produces greater prolongations of high quantal content currents compared to low quantal content currents (Kordas, 1972; Hartzell et al., 1975; Magleby and Terrar, 1975), indicating that with hydrolysis inhibited, effective transmitter concen- trations are prolonged upon release of many quanta relative to release of few quanta. At CNS glutamate synapses, it is unclear whether diffusion and glutamate uptake are rapid enough, relative to channel closing rate and fast receptor desensitization, to isolate the domains of individual transmitter quanta and to limit the time course of evoked EPSCs to that of mEPSCs.

To address the questions of whether effective glutamate concentrations are prolonged under conditions of enhanced evoked release and whether prolonged effective glutamate concentrations can influence synaptic current decays, we first examined EACs and EPSCs with conditions optimized for detecting effects of prolonged glutamate transients upon the time course of synaptic responses. We examined cells treated with cyclothiazide (CYZ) to enhance the sensitivity of non-NMDA receptors to transmitter and with the glutamate uptake inhibitor $\mathrm{D}, \mathrm{L}$ threo-3 hydroxyaspartate (THA; Balcar and Johnston, 1972) to diminish glutamate uptake into nerve terminals and glia. CYZ dramatically potentiates hippocampal non-NMDA receptor-mediated currents through a block of receptor desensitization (Patneau et al., 1993; Yamada and Tang, 1993; Zorumski et al., 1993) and an increase in the apparent affinity of receptors, reflected by increased potency of glutamate agonists and in a slowing of the offset of currents following rapid agonist removal (Patneau et al., 1993; Yamada and Tang, 1993). We have previously shown that treatment of neurons with $\mathrm{CYZ}$ can unmask a prolongation of EAC decays by THA and other glutamate uptake inhibitors (Mennerick and Zorumski, 1994).

With uptake inhibited, CYZ-treated EAC decays should be speeded upon reducing evoked release if transmitter transients are prolonged with high quantal output compared to low quantal output (Kordas, 1972; Hartzell et al., 1975; Magleby and Terrar, 1975; Trussell et al., 1993). To test this possibility, we manipulated the quantal content of evoked responses by changing extraccllular $\mathrm{Ca}^{2+}$ and $\mathrm{Mg}^{2+}$ concentrations ( $\left[\mathrm{Ca}^{2+}\right]_{o}$ and $\left[\mathrm{Mg}^{2+}\right]_{o}$ ). In the presence of $\mathrm{CYZ}$ and THA, synaptic currents of high quantal content were prolonged relative to currents of low quantal content from the same neurons (Fig. $2 A$, closed circles), indicating that with uptake inhibited, effective concentrations of glutamate are prolonged following release of many transmitter quanta.

Additionally, EAC decays in CYZ were speeded with reduced transmitter release even when uptake was intact (Fig. $2 A$, open circles), suggesting that uptake is insufficiently rapid to eliminate the longer glutamate transients following release of many quanta. This effect was not due to interactions between divalent cation concentrations and the effectiveness of CYZ since changes in decay rates were mimicked by depressing release through stimulation of adenosine receptors (Yoon and Rothman, 1991b; Lupica et al., 1992; Thompson et al., 1992) using the adenosine agonist 2-chloroadenosine (Fig. 2C,D). Also, the speeding of decays was not unique to EACs, since the changes in time course of EAC decays were mirrored by changes in EPSC decays obtained from dual recordings of two-neuron microislands (Fig. 2C,D)

THA became less effective at prolonging CYZ-treated EACs as glutamate release was reduced (Fig. $2 A$, compare open, closed circles; Fig. $2 B$ ), indicating that glutamate uptake plays a larger role in clearing synaptic glutamate after release of large numbers of quanta. The differential effects of THA suggest that slower decays of large quantal content currents are at least partly due to higher or longer effective concentrations of transmitter following release under these conditions. 


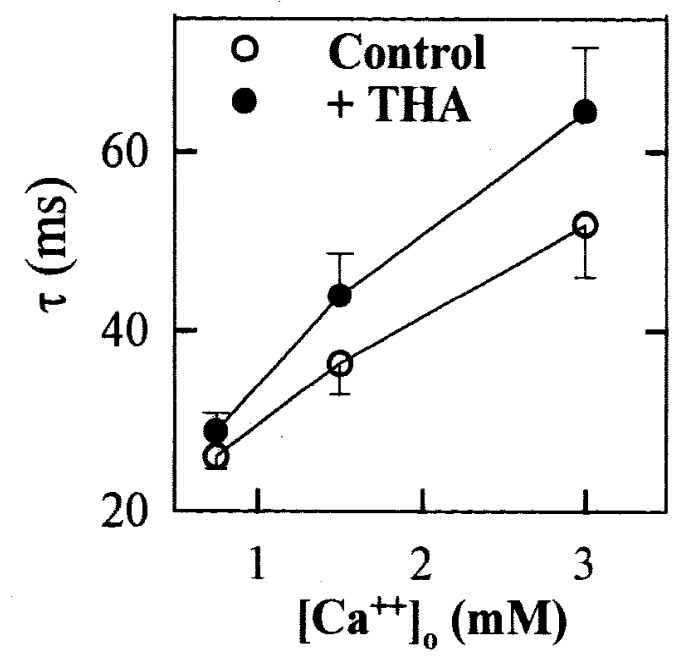

C

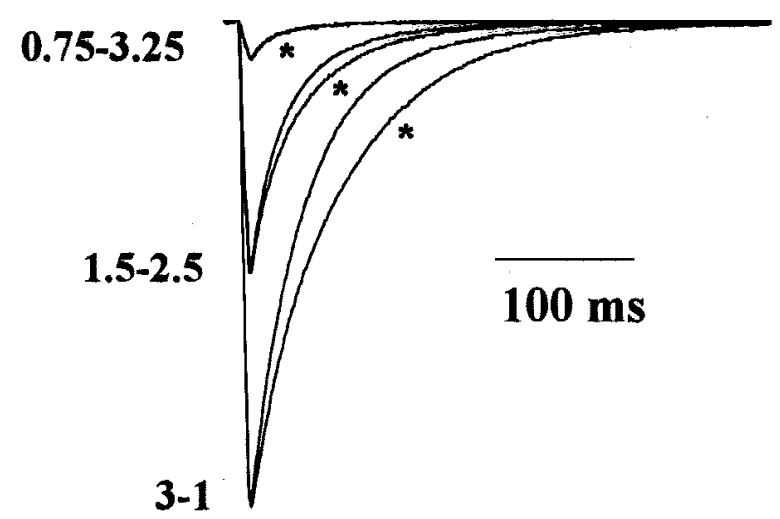

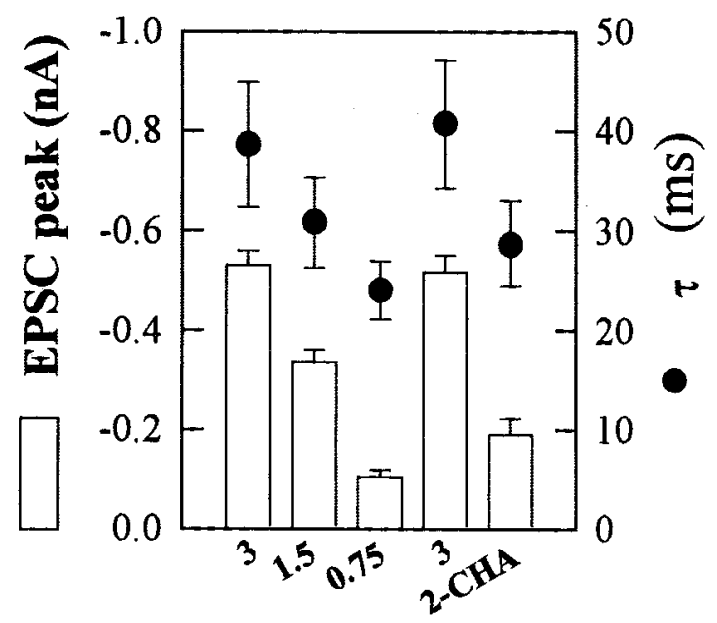

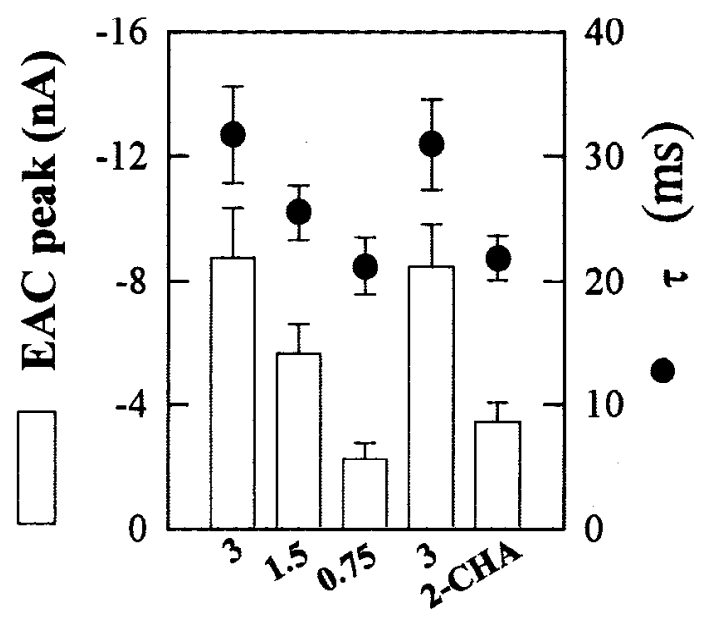

Figure 2. Prolongation of effective glutamate concentrations can be detected in CYZ-treated cells. $A$, The graph shows that both in the presence of $30 \mu \mathrm{M}$ THA to inhibit glutamate uptake (open circles) and with uptake intact (closed circles), reducing release of transmitter produced an increased rate of EAC decay $(n=12$ cells treated with $50 \mu \mathrm{M} \mathrm{CYZ}$ ). $\Lambda$ s the level of evoked release was reduced, the effect of THA upon the EAC decay was also reduced. For these experiments $\left[\mathrm{Mg}^{2+}\right]_{o}$ was raised as $\left[\mathrm{Ca}^{2+}\right]_{o}$ was lowered to keep the total divalent cation concentration constant at $4 \mathrm{~mm}$. $B$. The traces show an example of an EAC used to generate the plot in $A$. Asterisks indicate the THA-treated EACs. Since THA produced a depression of EAC peak anplitude (see texi), peaks at each [Ca $\left.{ }^{2+}\right] /\left[\mathrm{Mg}^{2+}\right]$ were scaled to the peak response in the absence of THA. Numbers to the left of the traces indicate $\left[\mathrm{Ca}^{2+}\right]_{0}\left[\mathrm{Mg}^{2+}\right]_{0}$. Stimulus-associated transients have been blanked. $C$ and $D$, Changes in peak amplitudes and decays of four CYZ-treated EPSCs from two-neuron microislands mirrored changes in the EACs of the presynaptic cells. Numbers below the graphs indicate $\left[\mathrm{Ca}^{2+}\right]_{0}$. A divalent cation concentration of $4 \mathrm{~mm}$ was maintained by adjusting $\left.\mid \mathrm{Mg}^{2+}\right\rfloor$. After obtaining responses in three $\mathrm{Ca}^{2+}$ concentrations, cells were returned to $3 \mathrm{mM} \mathrm{Ca}^{2+}$. Both peak amplitudes and decay rates returned to baseline levels. Another presynaptic modulator, 2-chloroadenosine (2-CHA, $1 \mu \mathrm{M})$, produced changes in peak amplitude and decay similar to those produced by altering divalent cation concentrations. In this experiment, postsynaptic neurons were maintained at a holding potential of -40 to $-5 \mathrm{mV}$ to limit the size of the peak EPSC in 3 $\mathrm{mM} \mathrm{Ca}^{2+}$ to $\sim 500 \mathrm{pA}$.

Under the high $\left[\mathrm{Ca}^{2+}\right]_{o}$ conditions of Figure $2, \Lambda$ and $B$, where the effects of THA were most pronounced, $\tau$ values from the best single exponential fits to the average response of individual cells revealed a highly significant difference between the decays of EACs treated with CYZ alone and the decays of EACs from the same cells in the presence of the combination of CYZ and THA ( $p<0.0001$; Fig. $2 B$ ). However, when biexponential fits were used to describe the data (two cells' de- cays could not be fit with the iterative fitting routine) neither $\tau_{f}, \tau_{s}$, or the relative contribution of $A_{f}$ to the total amplitude exhibited a significant difference in the THA versus control condition ( $p>0.05, n=10$ ). Since the effects of THA upon decays were unambiguous (Fig. $2 B$ ), and effects were highly significant when one exponential was used to describe the data, we interpret the lack of significant differences among bi-exponential components to mean that the effects of THA were 
Figure 3. CYZ-treated spontaneous FACs (sEACs) are unaffected by uptake inhibition. Evoked EACs and spontaneous EACs occurring between evoked EACs were obscrved on a single-neuron microisland. Before $\mathrm{CYZ}$ treatment (left panels), THA had no effect on the decays of either the evoked EACs (top left) or sEACs (bottom left). After CYZ application (right panels), evoked responses were prolonged by THA, but sEACs were not. SEAC traces represent averages of 11 to 61 isolated events in each condition. For evoked FACs, outward portions of stimulation-associated transients have been truncated. Divalent cations: $3 \mathrm{~mm}$

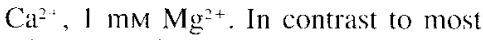
other experiments, EACs were obtained using a patch-clamp amplifier in order to reduce noise levels for the detection of small sEACs.
Baseline
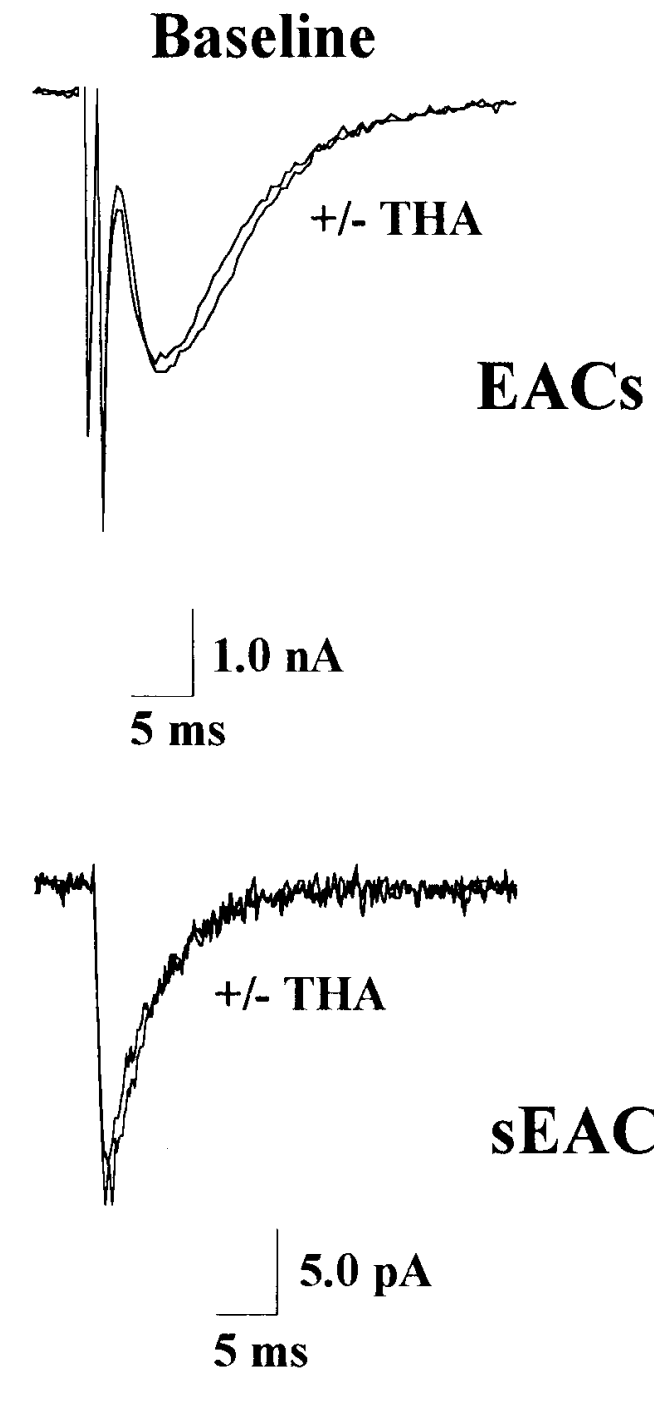

\section{$+\mathrm{CYZ}$}

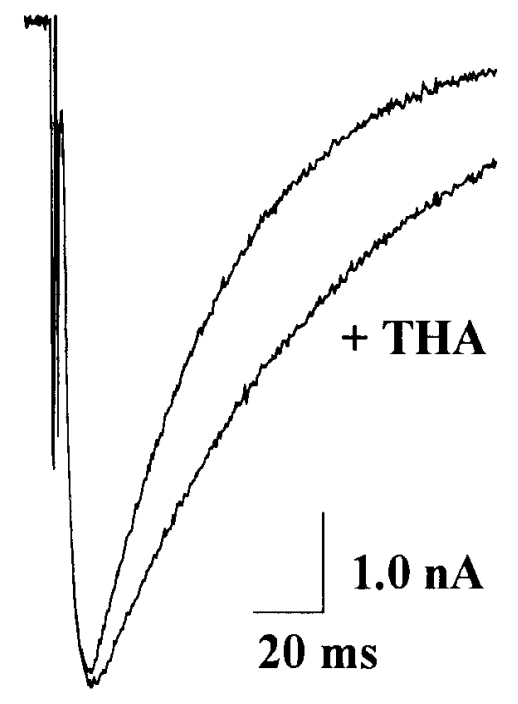

SEAs

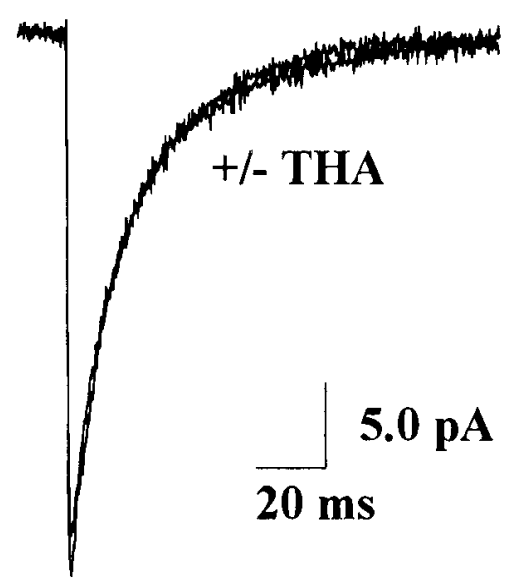

not selective for one particular component of decay in every cell.

As previously reported (Mennerick and Zorumski, 1994), THA also had a slight and variable depressive effect on the peak amplitude of EACs $(5 \pm 1 \%$ for the 12 cells contributing to Fig. 2). This effect was not associated with the degree of slowing of the EAC decays. The depressive effect of THA upon EAC peak amplitudes could be due to a buildup of glutamate during uptake inhibition (Isaacson and Nicoll, 1993; Barbour et al., 1994). However, even in the presence of CYZ we did not observe changes in holding currents during THA application like those recently reported in cerebellar slices (Barbour et al., 1994).

The change in effectiveness of THA with changes in divalent cation concentrations was not due to a direct interaction of divalent cations with THA or an effect of changing divalent cation concentrations upon uptake mechanisms, since the reduced effect of THA was also seen when monitoring spontaneous EACs (sEACs) simultaneously with evoked EACs from single-neuron microislands in the presence of a constant $\left[\mathrm{Ca}^{2}\right]_{0} /\left[\mathrm{Mg}^{2+}\right]_{0}$ (Fig. 3). SEACs in these experiments probably represent the release of single or small numbers of quanta, since their amplitude and time course closely mimicked those of MEPSCs recorded in the presence of TTX. In four neurons treated as in Figure 3, the evoked $\mathrm{EAC}$ in the presence of $\mathrm{CYZ}$ was prolonged $40 \pm 12 \%$ by $\mathrm{THA}$, representing a change in the optimal $\tau$ value from $60.13 \pm 12.16$ to $83.6 \pm 16.0 \mathrm{msec}$. In sEACs from the same neurons, the change in decay by THA was $-8.0 \pm 5.0 \%$, representing a change in optimal $\tau$ of $17.1 \pm 1.9$ to $15.8 \pm 1.8$ msec. We noted no consistent effect of THA upon SEAC peak amplitudes either in the absence $(4 \pm 6 \%$ depression, $n=4)$ or presence ( $2 \pm 4 \%$ depression, $n=4$ ) of $\mathrm{CYZ}$.

The faster decays of low quantal content EACs (Fig. 2) and sEACs (Fig. 3) relative to high quantal content EACs suggest that uptake is insufficiently rapid to limit the glutamate concentration time course of high quantal content events to that of low quantal content events. However, to examine directly whether glutamate transients are prolonged when uptake is intact, we inhibited uptake at time points following evoked transmitter release. For these experiments, we performed dual whole-cell recordings from glial cells and from neurons on single-neuron microislands, and we used glial depolarization to inhibit glutamate uptake (Barbour et al., 1991; Wyllie et al., 1991; Mennerick and Zorumski, 1994). This method of uptake inhibition allowed finer temporal control over the commencement of glutamate uptake inhibition than bath application of THA. Figure 4 shows that in the presence of $25 \mu \mathrm{M} \mathrm{CYZ}$, glial depolarization applied prior 

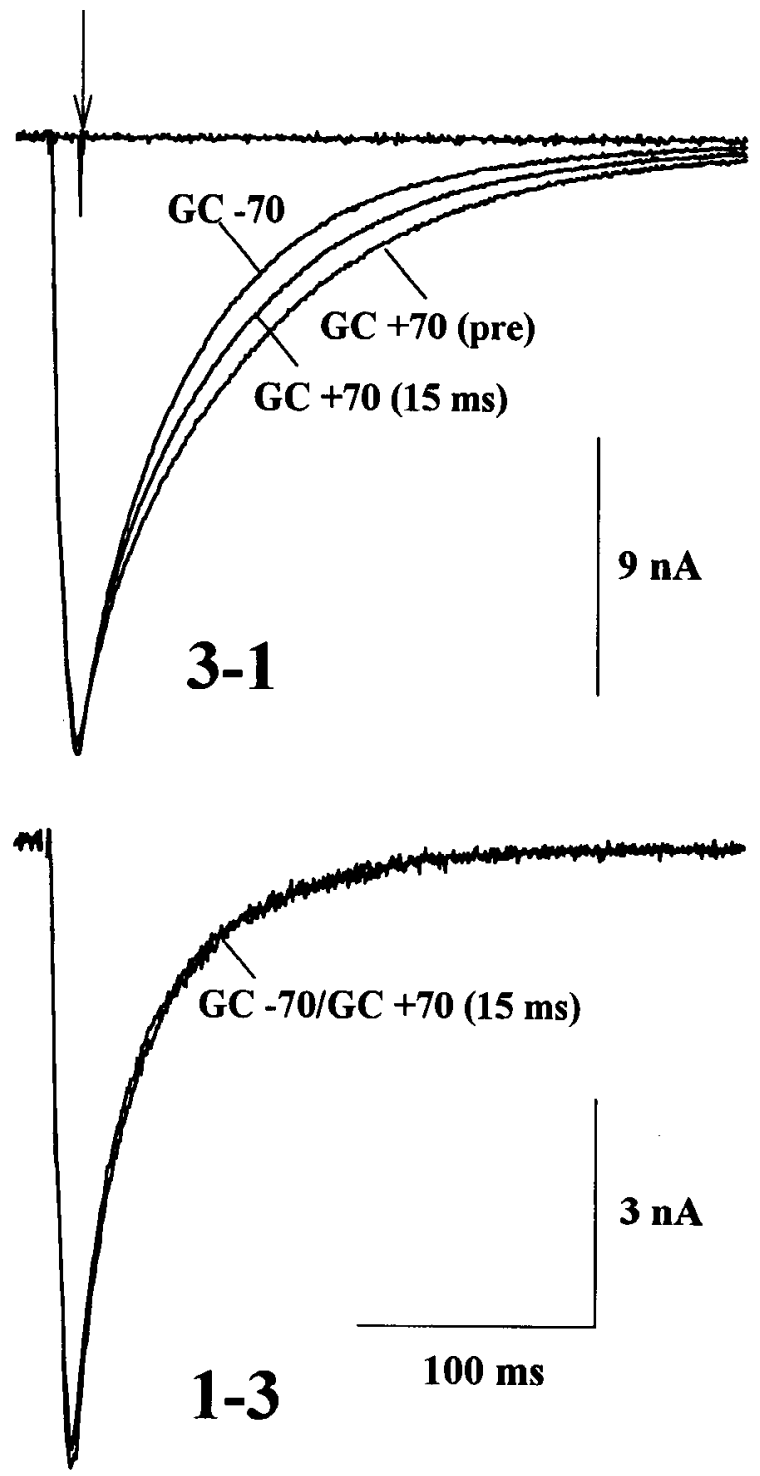

Figure 4. Uptake does not limit the time course of high quantal content glutamate transients to those of low quantal content transients. The upper traces represent EAC responses from a neuron on a microisland upon which an underlying glial cell $(G C)$ was simultaneously voltage clamped. In the presence of $3 \mathrm{mM} \mathrm{Ca}^{2+}, 1 \mathrm{mM} \mathrm{Mg}^{2+}, 25 \mu \mathrm{M} \mathrm{CY7}$, and with the glial cell voltage clamped at $-70 \mathrm{mV}$, the EAC decayed with a best-fit time constant of $49.0 \mathrm{msec}(G C-70)$. Glial cell step depolarization to $+70 \mathrm{mV}$ applied $10 \mathrm{sec}$ prior to $\mathrm{E} \Lambda \mathrm{C}$ stimulation produced a prolongation of the EAC decay [70.6 msec, $G C+70$ (pre)]. The same step glial depolarization applied $15 \mathrm{msec}$ following the evoked stimulation (arrow) also produced a prolongation of the EAC $[59.9 \mathrm{msec}$, $G C+70(15 \mathrm{~ms})]$. Glial depolarization applied in the absence of neuronal stimulation produced no current in the neuron (flat trace). The lower traces were obtained from the same neuron in the presence of 1.0 $\mathrm{mM} \mathrm{Ca}^{2+}$ and $3.0 \mathrm{mM} \mathrm{Mg}^{2+}(1-3)$. Glial depolarization $15 \mathrm{msec}$ following EAC stimulation produced almost no effect upon the EAC decay $[G C-70$ and $G C+70(15 \mathrm{~ms})$ traces are superimposed]. Decay time constants for the bottom traces were $31.5 \mathrm{msec}(-G C-70)$ and 32.2 msec $[G C+70(15 \mathrm{~ms})]$. Stimulus artifacts have been blanked.

to an evoked autaptic stimulus caused a prolongation of the neuronal EAC, as previously described (Mennerick and Zorumski, 1994). Additionally, glial depolarization begun $15 \mathrm{msec}$ following autaptic stimulation produced a prolongation of the EAC decay (Fig. 4, upper panel). In contrast, when the quantal content of the EAC was lowered, glial depolarization following stimu- lation produced no prolongation of the EAC (Fig. 4, lower panel). Similar results were seen in four other glial/ncuronal pairs. This result offers strong support for the idea that prolonged glutamate transients underlie the slower decays of high quantal content responses. For high quantal content responses, even with uptake intact (during the first $15 \mathrm{msec}$ following stimulation) sufficient glutamate can still remain for uptake inhibition to play a detectable role in prolonging the EAC. Furthermore, the data suggest that glutamate transients under some conditions can be much longer than previous estimates have suggested (Eccles and Jaeger, 1958; Clements et al., 1992).

Because the effect of uptake inhibitors upon evoked responses is augmented by both CYZ (Fig. 3) and by enhanced presynaptic release (Fig. 2A,B), we wondered whether CYZ's interaction with THA's effects could be due to a presynaptic potentiating action of $\mathrm{CYZ}$ rather than to its postsynaptic effects. To address this question, we examined the actions of CYZ in more detail. Similar to the results of others using conventional hippocampal cultures (Yamada and Tang, 1993), microisland mEPSCs were prolonged by CYZ (Figs. 3, lower panels; 5A,B), and the inadequacy of single exponential descriptions of decay rates became even more pronounced in the presence of CYZ. A summary of the effects of $50 \mu \mathrm{M} \mathrm{CYZ}$ upon the decay time course of mEPSCs is shown in Figure $5 B$. CYZ also tended to increase the peak amplitude of mEPSCs. In eight neurons, the increase in peak amplitude was $16 \pm 10 \%$. In many neurons, CYZ caused an increase in the apparent frequency of events (see also Yamada and Tang, 1993). The mean baseline frequency of mEPSCs was $3.3 \pm 1.3 \mathrm{~Hz}$, as compared with $10.5 \pm 3.1 \mathrm{~Hz}$ for the same cells in the presence of $50 \mu \mathrm{M} \mathrm{CYZ}(p<0.05$, paired $t$ test). This apparent frequency increase could be due to the unmasking, through the potentiating action of $\mathrm{CYZ}$, of events that were undetected in the baseline condition. However, the more conventional interpretation of an increase in the frequency of mEPSCs is that the agent has presynaptic potentiating effects (Fatt and Katz, 1952; Finch et al., 1990; Finch and Jackson, 1990; Malgaroli and Tsien, 1992).

Given the potential for presynaptic effects upon spontaneous mEPSC frequency, we examined whether some of the potentiating action of CYZ upon evoked non-NMDA EPSCs might be mediated presynaptically. To examine potential effects of CYZ upon evoked transmitter release, we took advantage of the dual nature of excitatory synaptic responses. Non-NMDA and NMDA components of EPSCs are modulated in parallel by agents that change the degree of evoked transmitter release in both hippocampal slices (Perkel and Nicoll, 1994) and in microcultures (Tong and Jahr, 1994). While CYZ consistently increased the peak amplitude of evoked non-NMDA EACs $(68 \pm$ $33 \%, n=4)$, NMDA EACs from the same neurons were not affected or were slightly depressed by CYZ (Fig. $5 C, D ; 15 \pm$ $11 \%$ depression, $n=4$ ). To enhance the chances of detecting a presynaptic potentiating effect of CYZ, we also recorded NMDA EACs in low $\mathrm{Ca}^{2+}$ solutions to avoid saturation of presynaptic or postsynaptic mechanisms. In 10 cells examined in $0.5 \mathrm{~mm}$ $\mathrm{Ca}^{2+}, 50 \mu \mathrm{M} C Y Z$ produced a $2 \pm 4 \%$ depression of the peak NMDA EAC. In a subset of five of these cells, $\left[\mathrm{Ca}^{2+}\right]_{\circ}$ was raised to $0.75 \mathrm{mM}$, producing a $59 \pm 11 \%$ increase in the NMDA response, indicating that despite the postsynaptic blocking effects of extracellular $\mathrm{Ca}^{2+}$ upon NMDA receptor channels (Ascher and Nowak, 1988; Jahr and Stevens, 1993), a presynaptic potentiation could be detected. It should be noted that in these experiments, concentrations of CNQX or NBQX normally 
A

\section{Ctrl}

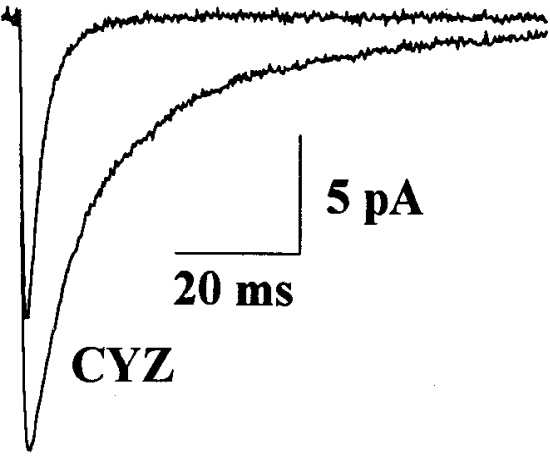

B1

B2

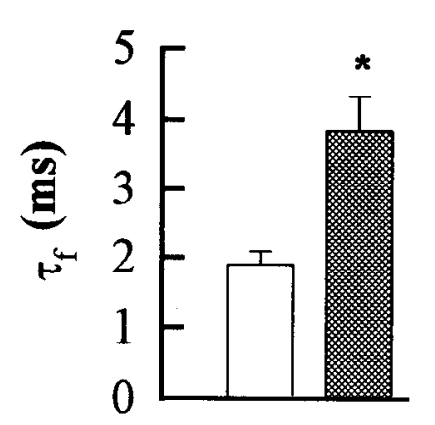

$\mathbf{C}$
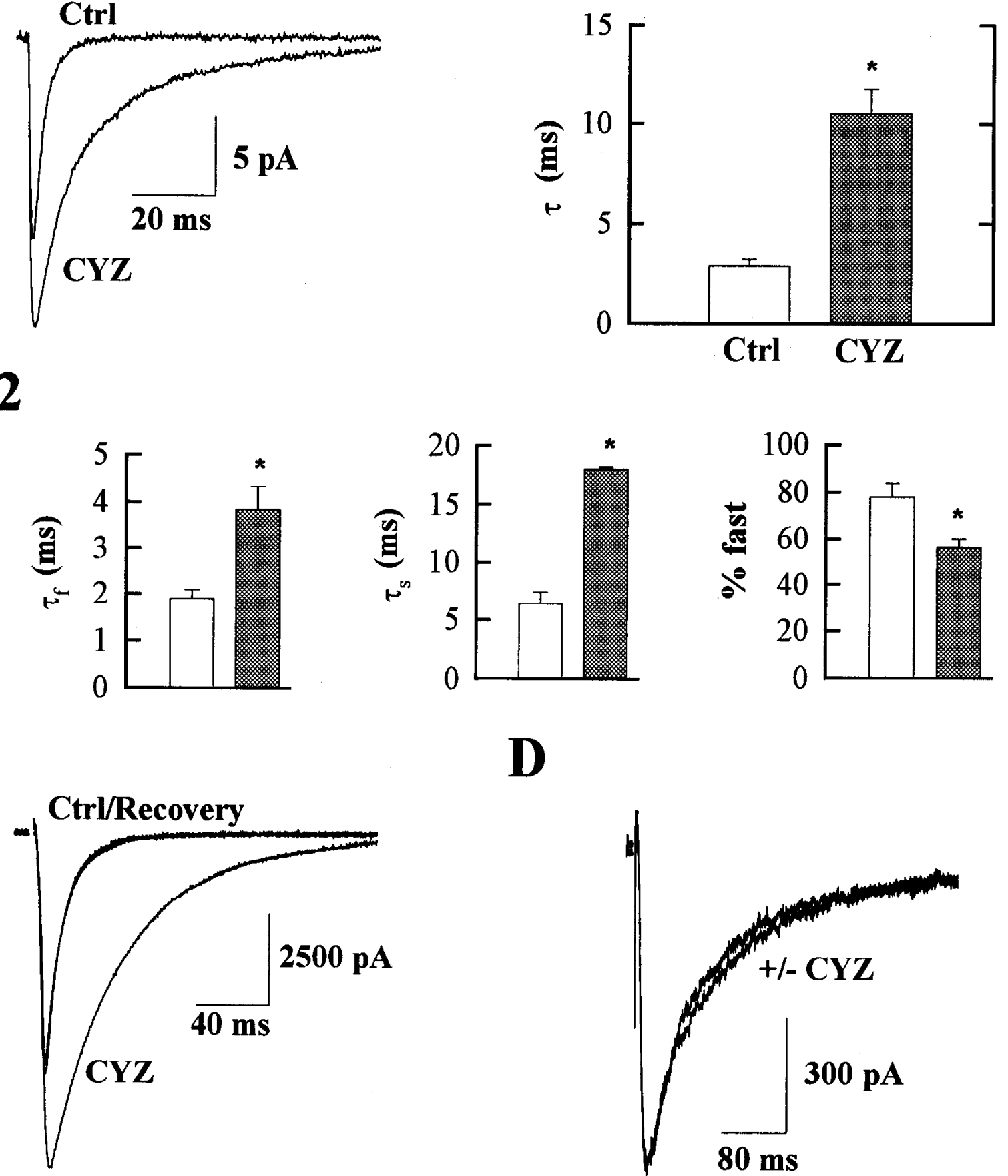

D

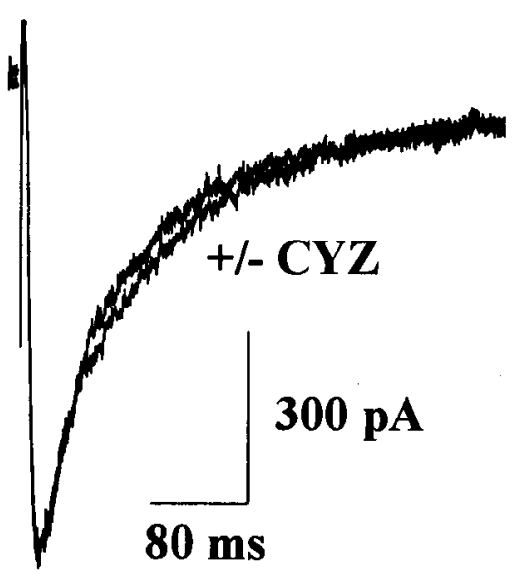

Figure 5. Cyclothiazide potentiates non-NMDA mEPSCs and evoked EACs but does not potentiate NMDA EACs. $A$, The traces show averages of 135 mEPSCs before (Ctrl) and 145 mEPSCs after $(C Y Z)$ treatment of the cell with $50 \mu \mathrm{M} C Y Z$. BI, The graph shows the change in the optimal

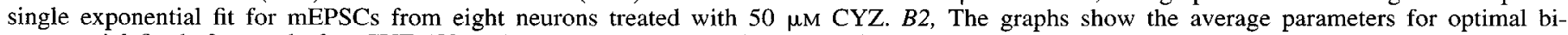
exponential fits before and after CYZ $(50 \mu \mathrm{M})$ treatment. Asterisks in $B 1$ and in $B 2$ denote $p<0.01$, paired $t$ test. $C$, An evoked EAC from a single-neuron microisland exhibited reversible potentiation with addition of CYZ $(50 \mu \mathrm{M})$ to the bath solution. The traces were obtained using a bath solution containing $2 \mathrm{mM} \mathrm{Ca}^{2+}$, no added $\mathrm{Mg}^{2+}, 10 \mu \mathrm{M}$ glycine and $50 \mu \mathrm{M}$ D-APV. $D$, Upon washing out D-APV and washing in $10 \mu \mathrm{M}$ NBQX, the cell in $C$ was stimulated to reveal an NMDA EAC in isolation. CYZ did not potentiate the NMDA EAC.

sufficient to abolish baseline non-NMDA EACs $(10 \mu \mathrm{M}$ or 1 $\mu M$, respectively) were not sufficient to abolish non-NMDA EACs in the presence of $50 \mu \mathrm{M}$ CYZ. It is not clear whether this effect is due to the higher apparent affinity of C.YZ-treated non-NMDA receptors for glutamate or if there is an additional direct effect of $\mathrm{CYZ}$ on the affinity of the receptors for these antagonists. The results of Figure 5 make it unlikely that CYZ's ability to unmask THA-induced slowing of EPSCs is mediated through presynaptic effects of CYZ.

As an additional test of a presynaptic effect of CYZ upon 
evoked autaptic currents, we examined the effect of CYZ upon paired-pulse modulation of autaptic responses. It has becn shown at a variety of synapses that presynaptic modulators will change the degree of paired-pulse modulation, with potentiators of presynaptic release favoring paired-pulse depression and inhibitors of presynaptic release favoring paired-pulse facilitation (Mallart and Martin, 1968; McNaughton, 1980). In a bath solution of 2 $\mathrm{mM} \mathrm{Ca}{ }^{2+}$ and $1 \mathrm{mM} \mathrm{Mg}^{2+}$, test EACs evoked $300-400 \mathrm{msec}$ following a conditioning EAC were depressed by $30 \pm 6 \%$ ( $n$ $=11$ cells). These rather long paired-pulse intervals were used so that there would be little contribution of postsynaptic receptor desensitization to paired-pulse modulation (Colquhoun et al., 1992; Trussell et al., 1993), and so that prolonged CYZ-treated responses could decay completely to baseline before a test stimulus was delivered. In the same cells, as a positive control, we raised $\left[\mathrm{Ca}^{2+}\right]_{0}$ from $2 \mathrm{mM}$ to $3 \mathrm{~mm}$. CYZ potentiated the peak amplitude of conditioning responses by $76 \pm 13 \%$, but had no significant effect on paired-pulse depression $(28 \pm 4 \%, p>$ $0.5)$. In contrast, raising $\left[\mathrm{Ca}^{2+}\right]_{o}$ produced only an $18 \pm 4 \%$ increase in peak amplitude of conditioning responses but significantly increased the degree of paired-pulse depression to $38 \pm$ $6 \%(p<0.001$, paired $t$ test). This experiment offers independent support that CYZ does not potentiate evoked EACs through a presynaptic action.

In summary, the data so far suggest that unlike diffusion and hydrolysis at the NMJ, the combination of diffusion and glutamate uptake is insufficiently fast to isolate the domains of individual evoked transmitter packets at hippocampal microisland glutamate synapses. This is reflected by CYZ-treated evoked EPSC decays that become faster with reduced transmitter release, even when high affinity glutamate uptake is intact, and by the ability for uptake inhibition, applied after evoked release, to prolong high quantal content EAC decays. The data also suggest that unlike acetylcholinesterase at the NMJ, uptake plays little role in clearing transmitter after release of small numbers of quanta. As with cholinesterase poisoning, uptake inhibition reveals a larger role of uptake in clearing transmitter following the release of many transmitter quanta. The results are consistent with a model in which diffusion alone is capable of rapidly clearing glutamate following spontaneous mEPSCs and evoked EPSCs of small quantal content, but where transmitter transients become more prolonged with higher quantal contents, leading to a more prominent role for uptake in transmitter clearance.

Figures 2-4 emphasize CYZ-treated neurons. The question remains whether the prolonged transmitter transients observed using CYZ-treated cells can influence the decays of untreated EPSCs. Because of the lower apparent affinity and rapid desensitization of receptors untreated with CYZ, it is possible that untreated receptors are not sensitive enough to detect the transmitter prolongations seen with CYZ-treated cells. As with CYZ treated EACs, untreated EACs showed a consistent correlation between the degree of evoked release and the optimal $\tau$ of synaptic currents. In four neurons treated as in Figure 3, optimal $\tau$ values of evoked baseline EACs were $10.1 \pm 1.8 \mathrm{msec}$ (range $5.7-13.8 \mathrm{msec}$ ) as compared with sEAC decays of $4.1 \pm 0.2$ msec (range $3.5-4.6 \mathrm{msec}$ ). This represented a $54 \pm 9 \%$ difference between individual evoked EAC and $\mathrm{sE} \Lambda \mathrm{C}$ optimal $\tau$ values without $\mathrm{CYZ}$ treatment. The largest differences were seen between the most slowly decaying evoked EACs and corresponding sEACs.

We considered several artifactual explanations for slowly decaying synaptic currents. First, synaptic currents under condi-
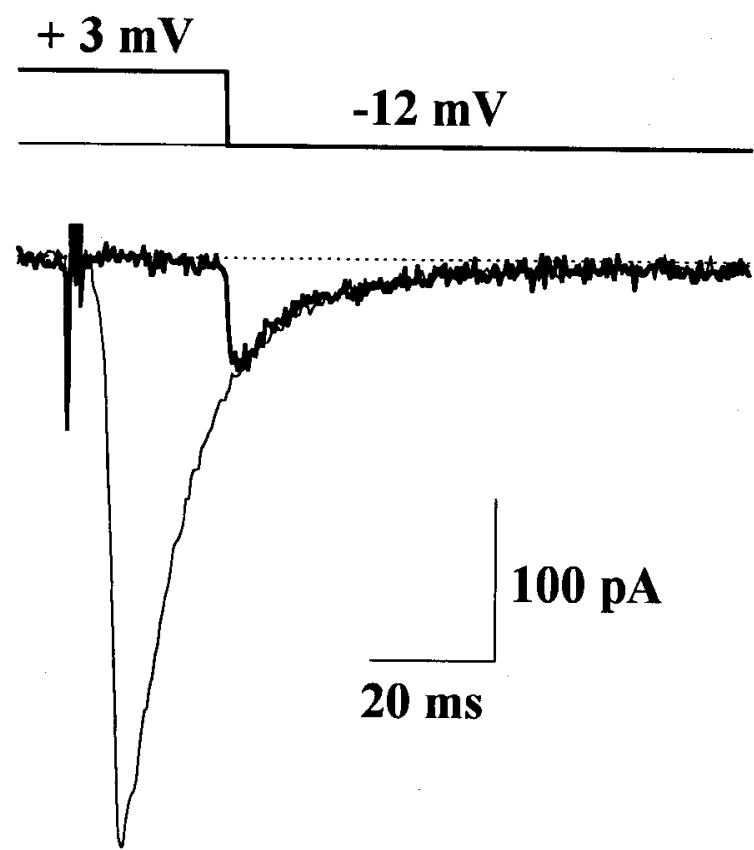

Figure 6. Late components of slowly decaying EPSCs are not caused by neuritic filtering. The bottom traces show EPSCs in response to stimulation of a presynaptic cell (not shown) during the voltage protocols represented by the top traces. In the first trial of the experiment (thin traces), the postsynaptic membrane potential was maintained at $-12 \mathrm{mV}$. The EPSC decayed with a time constant of $10.5 \mathrm{msec}$. In the next trial, the membrane potential was held near the reversal potential for the EPSC $(+3 \mathrm{mV}$ ) and stepped back to $-12 \mathrm{mV} 25 \mathrm{msec}$ following stimulation, during the late phase of the EPSC in the first trial. A trial identical to that of trial 2 , but without presynaptic stimulation, was digitally subtracted from trial 2 to eliminate the contribution of capacitive and voltage-gated current changes. Note that the synaptic current from trial 2 rises immediately to the level of the preceding EPSC and decays with a similar time course, indicating that the synaptic conductance is still activated at these late time points. The average of two runs of the experiment is shown.

tions of high quantal content could have a larger contribution of NMDA receptors, despite the use of $\mathrm{Mg}^{2+}$ and D-APV in recording solutions. However, the slow decay of cvoked EACs does not represent a contribution of NMDA receptors because raising the D-APV concentration from the usual $50 \mu \mathrm{M}$ to 200 $\mu \mathrm{M}$ produced no changes in the decays of evoked currents (50 $\mu \mathrm{M}, 9.7 \pm 2.0 \mathrm{msec} ; 200 \mu \mathrm{M}, 9.6 \pm 1.8 \mathrm{msec} ; n=7$ cells).

Spatial filtering of synaptic currents occurring at distal loci is another possible artifactual explanation for slowly decaying synaptic currents. Contrary to the results already presented, spatial filtering would be expected to influence both mEPSCs and evoked EPSCs. However, to examine whether spatial filtering is a cause of slowly decaying evoked synaptic currents, we performed an experiment similar to that described by others (Pearce, 1993; Barbour et al., 1994). In this experiment, a voltage step is applied from the reversal potential of the synaptic current relatively late in the time course of a control current to determine if the synaptic conductance is still active at these late times. Figure 6 shows the result of performing this experiment on one cell with a prolonged EPSC. The cell was first held at $-12 \mathrm{mV}$ while a presynaptic cell (not shown) was stimulated. The resulting EPSC had a time constant of $10.5 \mathrm{msec}$. In the next trial, the postsynaptic cell was held at $+3 \mathrm{mV}$, the reversal potential of the synaptic current, and $25 \mathrm{msec}$ following presyn- 
aptic stimulation, the postsynaptic membrane potential was stepped back to $-12 \mathrm{mV}$. After digitally subtracting a trial in which the postsynaptic membrane potential was stepped in the absence of presynaptic stimulation, it can be seen that the synaptic conductance was still active $25 \mathrm{msec}$ following presynaptic stimulation. The resulting current decayed with time course nearly identical to the original synaptic current. Similar results were observed in four other EPSCs from two-neuron microislands.

The apparent slower decays of large evoked EACs could also be caused by voltage-clamp errors due to pipette access resistance, inadequate feedback gain settings, or other clamp artifacts that might arise from the varied amplitude of currents under conditions of high and low quantal contents. To show that slower decay rates of large EACs are not primarily due to an artifact related to the size of currents, we approximately matched the peak postsynaptic conductance change under conditions of high and low quantal contents. We used the high affinity competitive antagonist NBQX (Sheardown et al., 1990) or the noncompetitive antagonist GYKI 52466 (Tarwana et al., 1989; Donevan and Rogawski, 1993; Zorumski et al., 1993) to reduce the amplitude of high quantal content EACs postsynaptically, and we used the $\mathrm{GABA}_{\mathrm{B}}$ agonist baclofen (Dutar and Nicoll, 1988; Harrison, 1990; Yoon and Rothman, 1991a) or low $\mathrm{Ca}^{2+}$ solutions to depress transmitter release (Fig. 7). For slowly decaying control EACs, postsynaptic depression produced currents with similar peak amplitudes but with slower decays than presynaptically depressed currents (Fig. 7A,C,D). Postsynaptically and presynaptically depressed EACs decayed at a similar rate in cells with rapidly decaying baseline EACs (Fig. $7 B, D$ ). On average, postsynaptically depressed EACs also exhibited significantly faster decays than baseline EAC decays (control decay, $9.2 \pm 0.7$ msec; NBQX decay, $8.0 \pm 0.9 \mathrm{msec}, p<0.01$; baclofen decay, $5.1 \pm 0.2$ msec, $p<0.01$ compared with NBQX matched controls; $n=25$; control for GYKI experiments, $10.7 \pm 1.5 \mathrm{msec}$; GYKI decay, $8.7 \pm 2.2, p=0.01$; baclofen decay, $5.8 \pm 0.3$, $p=0.01$ compared to GYKI matched controls; $n=7$ ). The effect of postsynaptic blockers on EAC decays could reflect an underestimation of the baseline decay rate due to voltage-clamp errors, although direct effects of the postsynaptic blockers on EAC decays are possible (see Discussion). The difference between the decays of postsynaptically and presynaptically depressed EACs matched for pcak amplitudes suggests that slow EAC decays under conditions of high quantal content are not primarily due to voltage-clamp errors arising from large currents.

The speeding of EAC decays under conditions of low quantal content could be due to increased synchrony in the release of transmitter. This would require that baclofen and low $\left[\mathrm{Ca}^{2+}\right]_{o}$, which presumably produce presynaptic depression through somewhat different mechanisms, both increase the synchrony of release, an effect that seems unlikely. However, stronger support for the idea that prolonged EPSCs are due to a prolonged effective concentration of transmitter would be gained if an effect of uptake inhibition upon EAC decays could be examined without CYZ treatment. Based on experiments using CYZ, the best chances of observing an effect of uptake inhibitors should be under conditions of enhanced evoked release. Therefore, we used elevated $\left[\mathrm{Ca}^{2+}\right]_{0}$ and reduced $\left[\mathrm{Mg}^{2+}\right]_{0}$ for these experiments. In cells from cultures maintained 13-16 d in vitro to allow synaptic connections and physical interactions between neurons and glial cells to mature, we found an effect of THA upon the time course of EACs without CYZ treatment in many neurons (Fig. 8). Experiments were performed by interleaving 6-18 control and THA trials for each cell. Under these conditions, we observed a reliable, reversible effect of THA in 16/25 neurons. A paired $t$ test using the average $\tau$ for each cell under each condition showed an statistically significant slowing of decay rates (control, $8.6 \pm 1.1 \mathrm{msec}$; THA, $10.1 \pm 1.4 \mathrm{msec}, p$ $=0.001$ ). As shown in Figure $8 B$, the largest effects of THA were seen in those cells with slowly decaying control EACs. Similar to CYZ-treated cells, lowering the level of presynaptic transmitter output speeded the decay of EACs and reduced the effect of THA upon the decay (Fig. $8 A 2, B$ ).

In most cells that showed an effect of THA upon the EAC decay, there appeared to be primarily a slowing of the late stages of the EAC decays (Fig. 8A). Although in individual cells biexponential fits showed changes in either $\tau_{f}$ or $\tau_{s}$, a statistically significant difference between the control and experimental conditions was observed only in the fast time constant of decay (control, $6.1 \pm 0.5 \mathrm{msec}$, vs THA, $6.6 \pm 0.6 \mathrm{msec}, p=0.01$ ). No significant difference was detected in the slow component of decay $(40.9 \pm 12.7$ vs. $36.4 \pm 0.6 \mathrm{msec})$ or in the relative contributions of the two components $(90 \pm 2 \%$ vs. $89 \pm 2 \%$ ).

The effects of THA upon the decays of high quantal content responses could still be explained by increased asynchrony of evoked transmitter release if THA, rather than inhibiting uptake, increased the asynchrony of release in high $\left[\mathrm{Ca}^{2+}\right]_{0}$. Two lines of evidence argue against this possibility. First, we have noticed that the frequency of sEACs is elevated in the first several hundred milliseconds following evoked release at microisland synapses, similar to a phenomenon observed at the neuromuscular junction (Zengel and Magleby, 1981). To address the possibility that THA increases the asynchrony of release, we examined the effect of THA upon the frequency of sEACs following evoked EACs on single-neuron microislands. In nine cells, we measured the frequency of sEACs for a period of $1 \mathrm{sec}$, beginning $40 \mathrm{msec}$ following evoked EAC stimulation. We found no change in the frequency of sEACs in the presence of THA compared to control (control, $13 \pm 4.7 \mathrm{~Hz}$; THA, $10 \pm 4.4 \mathrm{~Hz}$ ).

Secondly, glial depolarization had effects similar to those of THA (Fig. 9). Glial depolarization provides a nonpharmacological method of inhibiting uptake and, therefore, should not influence other features of neuronal transmitter release. Under conditions similar to those used for the experiments in Figure 8, we found that glial depolarization produced a reversible prolongation of EAC decays in 6/11 cells. In every case, the effects of glial depolarization upon the EAC time course were nearly abolished by lowering $\left[\mathrm{Ca}^{2+}\right]_{o}$ from $3.5 \mathrm{mM}$ to $1 \mathrm{mM}$ and raising $\left[\mathrm{Mg}^{2+}\right]_{0}$ from $0.5 \mathrm{~mm}$ to $3 \mathrm{~mm}$. Average single exponential decays were significantly prolonged relative to control (control, 9.0 $\pm 0.9 \mathrm{msec}$ vs $10.7 \pm 1.42 \mathrm{msec}, p<0.05$ ).

The effect of uptake inhibitors upon these large quantal content EACs in the absence of CYZ suggests that even under conditions of high transmitter output, desensitization of postsynaptic receptors does not fully dictate the decay of non-NMDA EPSCs. Therefore, at many microisland synapses, the processes of diffusion, glutamate uptake, and postsynaptic receptor desensitization are not sufficiently rapid to limit the decay time course of high quantal content synaptic currents to that of mEPSCs or EPSCs of low quantal content.

\section{Discussion}

Comparison with previous results

Microisland mEPSCs and evoked EPSCs were found to exhibit bi-exponential decays (see also Trussell et al., 1993; Barbour et 
A
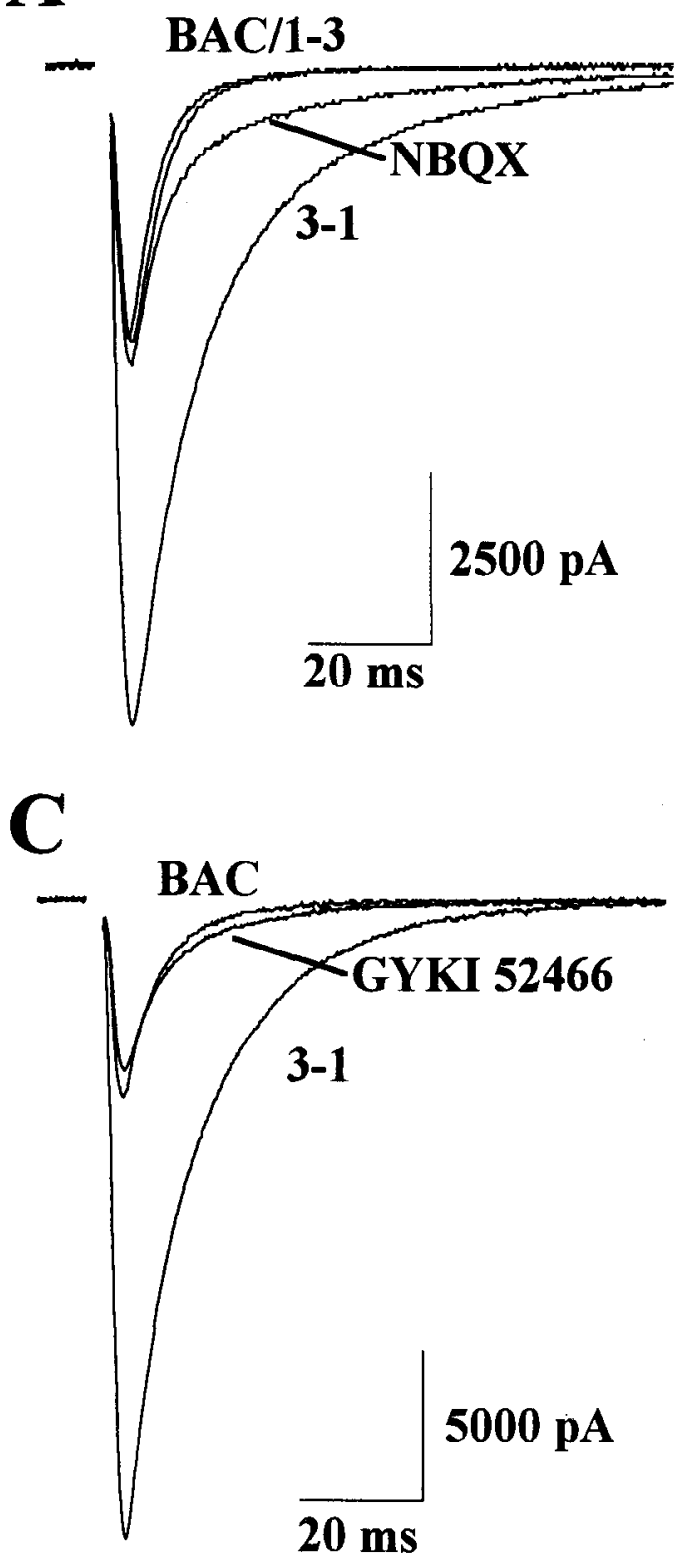

B

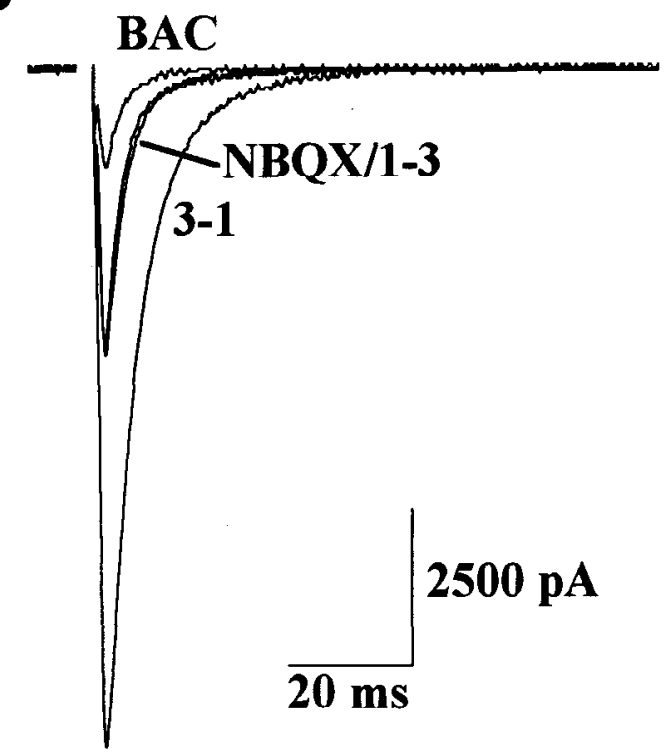

$\mathbf{D}$

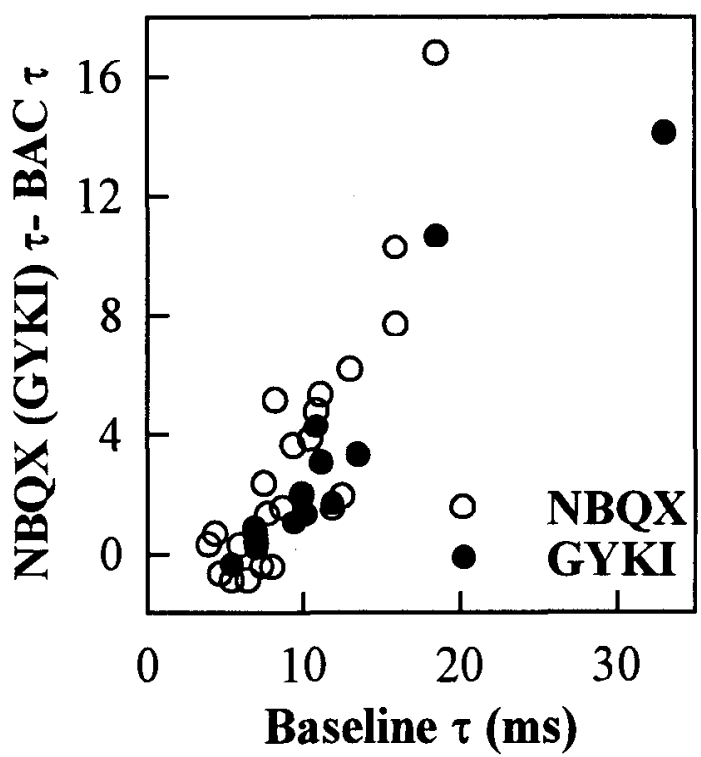

Figure 7. Increased transmitter release prolongs synaptic currents even in the absence of CYZ. $A$, The GABA $\mathrm{B}_{\mathrm{B}}$ receptor agonist baclofen (BAC, $20 \mu \mathrm{M})$ or $1 \mathrm{~mm} \mathrm{Ca}{ }^{2+}, 3 \mathrm{mM} \mathrm{Mg} \mathrm{Mg}^{2+}(1-3)$ was used to depress transmitter release. These agents reduced the peak response and speeded the decay of the baseline EAC. A submaximal concentration of the high affinity non-NMDA receptor antagonist NBQX (80-100 nM) approximately matched the peak conductance change with that of the presynaptically depressed EACs, but the NBQX-treated EAC decay was still greatly prolonged relative to the presynaptically depressed currents. The baseline EAC was obtained in a bath solution of $3 \mathrm{mM} \mathrm{Ca}^{2+}, 1 \mathrm{mM} \mathrm{Mg} \mathrm{Mg}^{2+}(3-1)$. Optimal $\tau$ values for each condition were $15.9 \mathrm{msec}(3-1), 12.8 \mathrm{msec}(N B Q X), 5.7 \mathrm{msec}(1-3), 5.2 \mathrm{msec}(B A C)$. B, In another cell, the EAC had a similar peak amplitude but decayed much more rapidly in the baseline 3-1 solution than the EAC shown in $A$. In this cell, NBQX and presynaptically depressed EACs decayed with a similar time course. In contrast to the cell in $A$, BAC produced a greater depression of the peak EAC than either the NBQX or 1-3 treatments. Optimal $\tau$ values for cach condition wcre $5.9 \mathrm{msec}(3-1), 3.7 \mathrm{msec}(N B Q X), 3.6 \mathrm{msec}(1-3)$, and $3.4 \mathrm{msec}(B A C)$. $C$, In another experiment, the non competitive non-NMDA receptor antagonist GYKI $52466(25 \mu \mathrm{M})$ depressed the peak EAC more than baclofen depressed the peak. Nevertheless, similar to results with NBQX, the EAC in the presence of GYKI 52466 was prolonged relative to the baclofen-treated EAC. Optimal $\tau$ values for this cell were $13.5 \mathrm{msec}$ (baseline), $10.1 \mathrm{msec}(G Y K I)$, and $6.7 \mathrm{msec}(B A C)$. D, A summary of 25 cells treated with NBQX and baclofen and of 12 cells treated with GYKI 52466 and baciofen shows that cells with slowly decaying baseline EACs were those with a large difference between the decays of postsynaptically and presynaptically depressed EACs. Peak EAC amplitudes in the presence of NBQX were matched to within $6 \pm 10 \%$ of the baclofen-depressed peaks. Peak amplitudes in the presence of GYKI 52466 were depressed by $16 \pm 10 \%$ relative to peak amplitudes in the presence of baclofen. Stimulus-associated transients were blanked for traces in $A-C$. 
A1

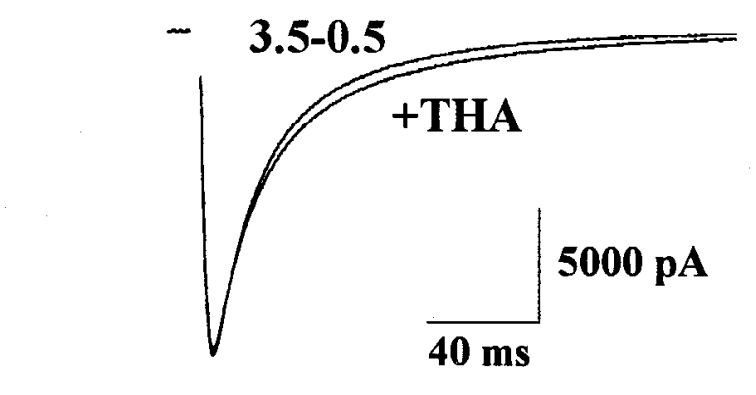

A2

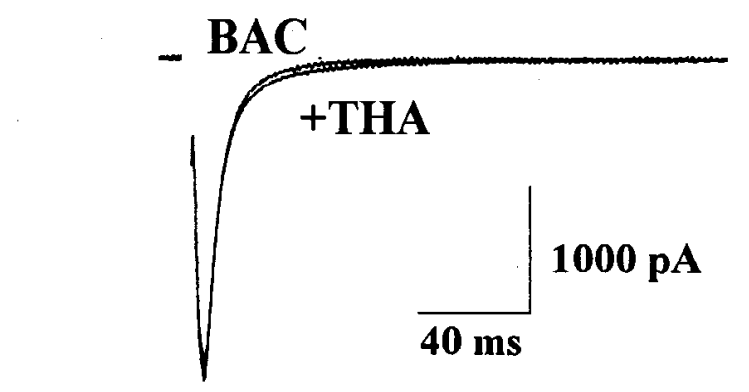

B

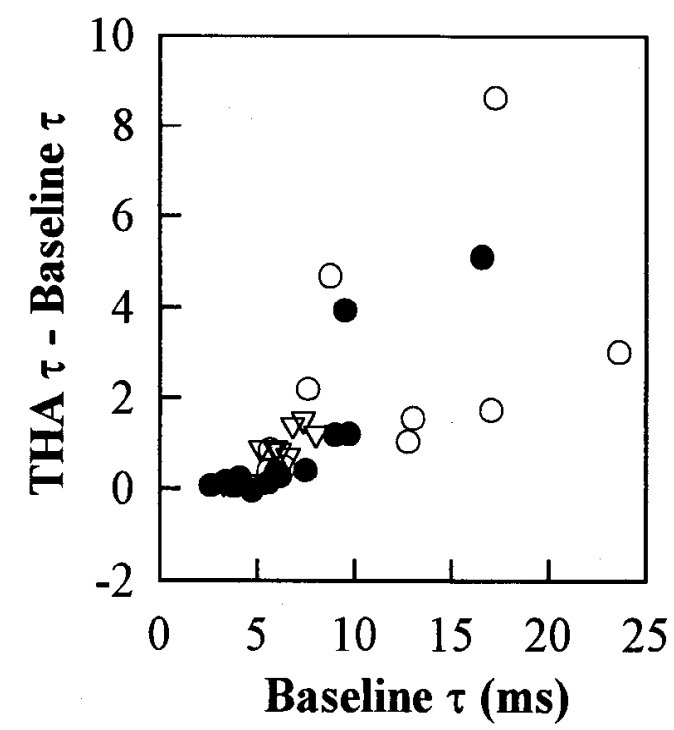

Figure 8. Uptake inhibition can prolong slowly decaying EACs in the absence of CYZ. A1, A slowly decaying EAC was prolonged by $30 \mu \mathrm{M}$ THA. $A 2, \mathrm{BAC}(20 \mu \mathrm{M})$ speeded the decay of the EAC, and the effect of THA was reduced in the presence of baclofen. $B$, The graph shows the difference between optimal $\tau$ values of THA-treated and baseline responses, plotted against the baseline $\tau(n=25$ cells). The slowest EACs were those most likely to be prolonged by THA. Open circles represent cells that were also treated with BAC. Open triangles represent the responses of these cells during BAC treatment. For these experiments, the baseline solution contained $3.5 \mathrm{mM} \mathrm{Ca}^{2+}$ and $0.5 \mathrm{~mm}$ $\mathrm{Mg}^{2+}$ to enhance release, and cells maintained 15-16 $\mathrm{d}$ in vitro were used. In the EAC traces in $A$, stimulus-associated transients have been blanked.
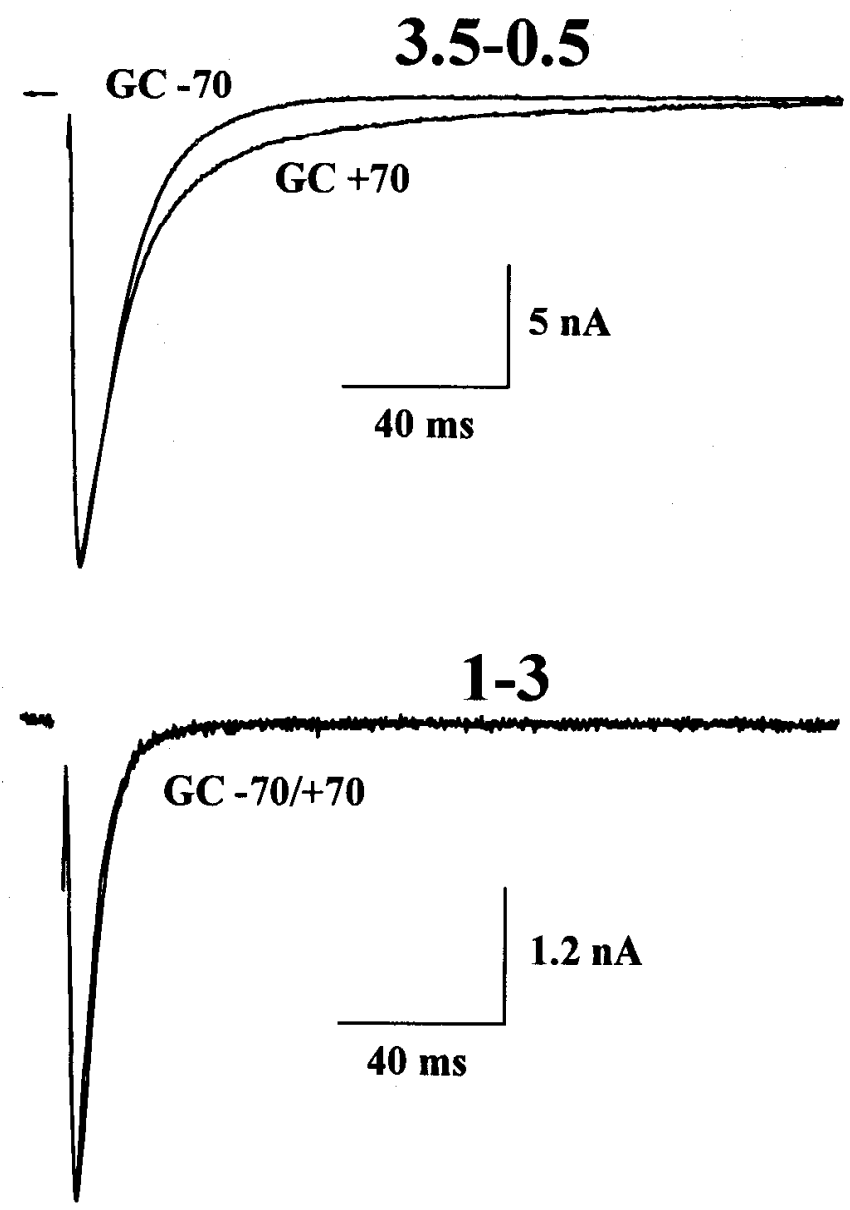

Figure 9. Glial depolarization can prolong high quantal content EACs. Dual recordings from a neuron and a glial cell on a single-neuron microisland were performed. Top panel, The traces show average EACs from the neuron in an extracellular bath solution of $3.5 \mathrm{mM} \mathrm{Ca}^{2+}$ and $0.5 \mathrm{mM} \mathrm{Mg}^{2+}(3.5-0.5)$, while the underlying glial cell was voltage clamped at either $-70 \mathrm{mV}(G C-70)$ or $+70 \mathrm{mV}$, applied for $12 \mathrm{sec}$ beginning $10 \mathrm{sec}$ prior to autaptic stimulation $(G C+70)$. Best fit $\tau$ values for single exponential fits were $11.4 \mathrm{msec}(G C-70)$ and 15.3 msec $(G C+70)$. Bottom panel, From the same pair of cells, when the bath solution was changed to one containing $1 \mathrm{mM} \mathrm{Ca}^{2+}$ and $3 \mathrm{~mm}$ $\mathrm{Mg}^{2+}(1-3)$, the effect of glial depolarization was abolished. Best fit $\tau$ values in the low $\mathrm{Ca}^{2+}$ solution were $5.1 \mathrm{msec}(G C-70)$ and $5.1 \mathrm{msec}$ $(G C+70)$. Stimulus artifacts have been blanked.

al., 1994). Although microisland mEPSC decays are similar to glutamate-mediated channel burst durations (Vyklicky et al., 1991) and to oftset decays of currents in response to brief glutamate pulses to outside-out patches (Colquhoun et al., 1992), it sccms unlikely that the values of the two components detected in evoked EPSC decays correspond to any one single channel parameter; the results of Figures 2-9 suggest that evoked current decays are likely to be the complicated product of several presynaptic and postsynaptic factors.

A major conclusion of the present work is that conditions that augment transmitter release can prolong non-NMDA synaptic currents by increasing the effective transmitter lifetime following evoked release. Transmitter lifetime at the NMJ, even with large quantal contents, is limited by diffusion and hydrolysis such that there essentially no receptor reactivation or spill-over of transmitter between adjacent synaptic sites (Kordas, 1972; Magleby and Stevens, 1972; Anderson and Stevens, 1973; Hartzell et al., 
1975; although see Giniatullin et al., 1993). Our results suggest that at many microisland synapses, the processes of diffusion, uptake, and receptor desensitization are insufficiently rapid to limit the domains of individual transmitter quanta and to limit the decay of evoked EPSCs to that of mEPSCs. Particularly surprising may be our finding that inhibition of uptake well after synaptic release can prolong EACs. Assuming a 5 msec synaptic delay between autaptic stimulation and synaptic release, Figure 4 suggests that even with uptake intact, measurable glutamate remains present for at least $10 \mathrm{msec}$ under the conditions of this experiment. It will be interesting to further elucidate the role of receptors, transporters, binding proteins, and physical barriers in hindering the clearance of glutamate following synaptic release.

Another important conclusion of the present study is that uptake plays a more prominent role in terminating the actions of glutamate under conditions of high quantal output than under conditions of low quantal output. Despite CYZ treatment, uptake inhibition had no effect upon sEAC decays, although in the same neurons, prolongations of evoked EACs were reliably detected. This result indicates that diffusion rapidly clears transmitter under conditions of low quantal content before uptake is activated. Similar to glutamate uptake inhibition, cholinesterase inhibition at the neuromuscular junction prolongs synaptic currents of large quantal content more than currents of small quantal content (Kordas, 1972; Magleby and Terrar, 1975). However, unlike the present results, cholinesterase poisoning produces significant prolongations of miniature synaptic events (Fatt and Katz, 1952). The differential effect of cholinesterase inhibition upon events of large quantal content is most likely due to the smaller average distance between activated release sites, permitting cooperative interactions between transmitter from adjacent release sites at overlapping postsynaptic receptor domains (Hartzell et al., 1975).

Differential effects of uptake inhibitors upon large evoked release events have also been observed for $\gamma$-aminobutyric acid (GABA) synaptic responses in hippocampal slices. GABA uptake inhibitors are effective in prolonging inhibitory currents only when strong stimulating shocks are used (Isaacson et al., 1993), which is presumably analogous to enhancing release with high $\left[\mathrm{Ca}^{2+}\right]_{o}$ and low $\left[\mathrm{Mg}^{2+}\right]_{o}$ in the present studies. One difference between inhibitory currents in hippocampal slices and microisland EPSCs is that with uptake intact, GABA responses obtained using weak and strong stimuli both decay with a similar time course (Isaacson et al., 1993). Therefore, GABA uptake may be sufficiently rapid to limit the decay rate of large evoked responses to that of small currents or mIPSCs where diffusion plays the primary role in clearing transmitter. The more prominent role of uptake in clearing glutamate following release of many quanta, combined with our previous finding that an effect of uptake inhibition upon non-NMDA EPSCs can be unmasked with CYZ treatment (Mennerick and Zorumski, 1994) may help explain the previous reported lack of effects of uptake inhibitors upon the decay of EPSCs (Hestrin et al., 1990b; Isaacson and Nicoll, 1993; Sarantis et al., 1993).

Our data suggest that the slowest currents should be those most shaped by receptor desensitization. However, the differential effect of uptake inhibition upon slower decaying currents in cells untreated with CYZ suggests that even with prolonged transmitter actions following release of many quanta, receptor desensitization has not reached its full extent. These data also suggest that CYZ's ability to unmask an effect of uptake inhibition upon evoked responses (Mennerick and Zorumski, 1994;
Fig. 3) may be primarily due to CYZ's enhancement of the apparent affinity of receptors rather than through prevention of receptor desensitization.

The present results are similar to recent findings from a glutamatergic calyceal synapse (Trussell et al., 1993), and cerebellar slices (Barbour et al., 1994), two preparations where prolonged effective glutamate lifetimes have been implicated in more slowly decaying EPSCs. Our results suggest that understanding the mechanisms underlying variability in effective glutamate concentrations at microisland synapses will yield insights into synaptic actions of glutamate in more intact preparations. Considerable variability exists in the estimates of decay rates of non-NMDA EPSCs recorded in CNS slice preparations, particularly when fiber tract stimulation is compared with minimal stimulation of synaptic responses (Hestrin et al., 1990a; Jonas et al., 1993). While some of this variability has been linked to different postsynaptic receptor properties of the neurons involved (Hestrin, 1993; Livsey et al., 1993) or to artifacts of inadequate voltage clamp (Hestrin et al., 1990a; Williams and Johnston, 1991), it is likely that the presynaptic influences observed at microisland synapses might also make a physiologically important contribution to this variability.

\section{Possible explanations for slowly decaying EPSCs}

One possible explanation for apparently slower EPSC decays is that conditions of high quantal content promote prolonged asynchronous release of transmitter following stimulation. Such asynchrony could go unresolved in the decay of EPSCs (Katz and Miledi, 1979). We cannot fully rule out some role for asynchronous release in prolonged EAC and EPSC decays. However, the differential effect of THA and glial depolarization on EPSCs of high quantal content (Figs. 2, 4, 8, 9) argues strongly that the prolongations of synaptic current decays are largely due to prolonged effective transmitter concentrations. It is also possible that prolonged asynchronous release contributes to prolonged effective transmitter concentrations observed under conditions of high quantal content. Indeed, the distinction between prolonged transmitter concentrations and asynchronous release becomes blurred if asynchronous release from individual presynaptic release sites occurs rapidly relative to the rate of transmitter clearance following evoked release.

With CYZ-treated cells, changes in decay rates were easily detectable, with average differences in optimal $\tau$ values of 10 20 msec occurring between high $\mathrm{Ca}^{2+}$ and low $\mathrm{Ca}^{2+}$ solutions (Fig. 2). With the faster decays of untreated cells, we were concerned that underestimation of peak amplitudes due to clamp errors with large responses could result in artifactually prolonged synaptic currents. However, by matching the conductance change elicited in the presence of presynaptic blockers to responses depressed with postsynaptic receptor antagonists, we showed that at least in the case of the slowest currents, the speeding of decays with reduced quantal content is not primarily due to systematic variations in the contribution of clamp errors to the decay rate of synaptic currents. Nevertheless, a comparison between the decays in the presence of postsynaptic blockers and presynaptic inhibitors remains semiquantitative, since postsynaptic blockers may speed decays of EPSCs relative to baseline decays due to a block of receptor-mediated buffered diffusion by competitive antagonists (Katz and Miledi, 1973; Magleby and Terrar, 1975; Pennefather and Quastel, 1981) or by potential direct effects on receptor channel properties by the noncompetitive antagonist GYKI 52466 (Zorumski et al., 1993). 
Inadequate spatial voltage clamp could also explain slowing of synaptic currents (Johnston and Brown, 1983; Hestrin et al., 1990a; Spruston et al,, 1994). Several lines of evidence argue against this explanation for slowly decaying synaptic currents. First, we have previously shown that spatial clamp variations are unlikely to explain much of the within-cell variability in decay times of microisland synaptic events, since rise times of microculture mEPSCs are not correlated with decay times or peak amplitudes in individual cells (Mennerick et al. 1994). Second, for spatial clamp errors to explain the results of Figure 7 , one must postulate that synapses close to the soma are preferentially activated under conditions of low quantal content. Third, we performed a direct test to show that synaptic conductances are still active at late time points during slowly decaying evoked EPSCs. Finally, as with other clamp error explanations, a spatial clamp explanation for slow EPSC decays is difficult to reconcile with the differential effect of THA upon slowly decaying currents.

Our results provide some insight into the mechanisms underlying variability in EPSC decay rates between cells. Although the largest currents in a given baseline bath solution tended to be those with the slowest decays, there were also examples of large currents that decayed rapidly (compare Fig. $7 A, B$ ). Differences in postsynaptic receptor channel kinetics are unlikely to contribute greatly to this difference since the current decays became more similar as presynaptic release was reduced. Differences in the effectiveness of glutamate uptake do not underlie the variation since this would predict a greater influence of uptake inhibition upon faster decaying currents, a result opposite to the one obtained in Figure 8.

Two non-mutually exclusive mechanisms probably underlie the variations in decay rates seen in individual cells with varied quantal contents and also the variations between cells in a given extracellular environment. First, prolonged decays could represent the repeated binding of transmitter to a single population of postsynaptic receptors following evoked release. Rebinding of transmitter would have an important influence upon EPSC decays if conditions that promote high quantal content also promote multiquantal release from individual release sites (Tong and $\mathbf{J}$ ahr, 1994). If rebinding of transmitter underlies prolonged EPSC's, differences in decay rates between cells could be explained by differences in the capability for multivesicular release or by differences in buffered diffusion from the synaptic cleft due to physical barriers and to the binding of transmitter.

Secondly, prolonged EPSCs could occur because individual quanta from separate release sites are capable of diffusing to and cooperatively activating overlapping populations of receptors. This possibility is more consistent with the hypothesis that evoked release from individual active zones is all or none (Korn et al., 1982; Korn and Faber, 1991; but see Katz and Miledi, 1979). Spill-over has been proposed to account for prolonged currents at other synapses (Hartzell et al., 1975) and has been reported at inhibitory synapses in several $\mathrm{CNS}$ preparations ( $\mathrm{Fa}-$ ber and Korn, 1988; Isaacson et al., 1993). Under conditions of low quantal content, spill-over would not generate sufficient glutamate concentrations for receptor activation in regions of transmitter overlap since activated release sites would tend to be separated by large distances. Under conditions of high quantal content, the average distance between activated relcase sites would be smaller, allowing glutamate concentrations in overlapping domains to reach levels sufficient for receptor activation. If spill-over is the primary mechanism of prolonged EPSCs, dif- ferences in decay rates between cells could result from differences in distances between activated release sites. For instance, cells like that depicted in Figure $7 A$ may possess presynaptic terminals like those of mossy fiber synapses on CA3 cells, where individual boutons have many closely adjacent active zones (Amaral and Dent, 1981; Chicurel and Harris, 1992). In contrast, Figure $7 B$-like cells may possess terminals similar to Schaffer collateral synapses upon CAI cells, which have only one or a few active zones per synaptic bouton (Sorra and Harris, 1993) and where overlap of transmitter domains may be less likely. Variability in numbers of extrasynaptic receptors in regions of transmitter overlap could also explain differences in decay rates between cells.

The relative contributions of rebinding and spill-over to prolonged EPSCs should determine the conditions under which EPSC decays would be altered by presynaptic mechanisms in the intact CNS. If rebinding of transmitter following multivesicular release is the primary mechanism generating prolonged EPSCs, then slower EPSCs should be generated by enhancing the probability of release, even when only a single release site is activated. Alternatively, if diffusion from many release sites is required for prolonged EPSCs, slowed EPSCs in the intact hippocampus might be apparent only with the synchronous activity of many axons, since individual axons often give rise to only a few points of synaptic contact with individual postsynaptic targets (Andersen, 1987).

Finally, there are also likely to be physiological effects of spill-over and varied transmitter lifetimes over a range of glutamate concentrations that would produce undetectable changes in the decays of non-NMDA EPSCs. As shown by the ability of CYZ to unmask effects of uptake inhibitors on the decays of many EACs, non-NMDA receptors are probably weak detectors of residual glutamate. Metabotropic glutamate receptor activation (Sladeczek et al,, 1985; Forsythe and Clements, 1990), NMDA receptor activation (Patneau and Mayer, 1990), and nonNMDA receptor desensitization (Trussell and Fischbach, 1989; Thio et al., 1991) should all occur at lower residual glutamate concentrations than those necessary for non-NMDA receptor activation.

\section{References}

Amaral DG, Dent JA (1981) Development of the mossy fibers of the dentate gyrus: a light and electron microscopic study of the mossy fibers and their expansions. J Comp Neurol 195:51-86.

Andersen PO (1987) Properties of hippocampal synapses of importance for integration and memory. In: Synaptic function (Edelman GM, Gall WE, Cowan WM, eds), pp 403-429. New York: Wiley.

Anderson CR, Stevens CF (1973) Voltage clamp analysis of acetylcholine produced end-plate current fluctuations at frog neuromuscular junction. J Physiol (Lond) 235:655-691.

Ascher P, Nowak L (1988) The role of divalent cations in the $\mathrm{N}$-methyl-D-aspartate responses of mouse central neurones in culture. J Physiol (Lond) 399:247-266.

Balcar VJ, Johnston GAR (1972) The structural specificity of the high affinity uptake of L-glutamate and L-aspartate by rat brain slices. J Neurochem 19:2657-2666.

Barbour B, Brew H, Attwell D (1991) Electrogenic uptake of glutamate and aspartate into glial cells isolated from the salamander (Ambystoma) retina. J Physiol (Lond) 436:169-193.

Barbour B, Keller BU, Llano I, Marty A (1994) Prolonged presence of glutamate during excitatory synaptic transmission to cerebellar Purkinje cells. Neuron 12:1331-1343.

Bekkers JM, Stevens CF (1991) Excitatory and inhibitory autaptic currents in isolated hippocampal neurons maintained in cell culture. Proc Natl Acad Sci USA 88:7834-7838.

Chicurel ME, Harris KM (1992) Three-dimensional analysis of the 
structure and composition of CA3 branched dendritic spines and their synaptic relationships with mossy fiber boutons in the rat hippocampus. J Comp Neurol 325:169-182.

Clements JD, Lester RA. Tong G, Jahr CE, Westbrook GL (1992) The time course of glutamate in the synaptic cleft. Science 258:1-1501.

Colquhoun D, Jonas P, Sakmann B (1992) Action of brief pulses of glutamate on AMPA/kainate receptors in patches from different neurones of rat hippocampal slices. J Physiol (Lond) 458:261-287.

Curtis DR, Duggan AW, Johnston GAR (1970) The inactivation of extracellularly administered amino acids in the feline spinal cord. Exp Brain Res 10:447-462.

Donevan SD, Rogawski MA (1993) GYKI 52466, a 2,3-benzodiazepine, is a highly selective, noncompetitive antagonist of AMPA/kainate receptor responses. Neuron 10:51-59.

Dutar P, Nicoll RA (1988) Pre- and postsynaptic GABA $_{B}$ receptors in the hippocampus have different pharmacological properties. Neuron 1:585-591.

Eccles JC, Jaeger JC (1958) The relationship between the mode of operation and the dimensions of the junctional regions at synapses and motor end-organs. Proc R Soc Lond [Biol] 148:38-56.

Ellis KJ, Duggleby G (1978) What happens when data are fitted to the wrong equation? Biochem .J 171:513-517.

Faber DS, Korn H (1988) Synergism at central synapses due to lateral diffusion of transmitter. Proc Natl Acad Sci USA 85:8708-8712.

Fatt P, Katz B (1952) Spontaneous subthreshold activity at motor nerve endings. J Physiol (Lond) 117:109-128.

Finch DM, Jackson MB (1990) Presynaptic enhancement of synaptic transmission in hippocampal cell cultures by phorbol esters. Brain Res 518:269-273.

Finch DM, Fisher RS, Jackson MB (1990) Miniature excitatory synaptic currents in cultured hippocampal neurons. Brain Res 518:257268.

Forsythe ID. Clements JD (1990) Presynaptic glutamate receptors depress excitatory monosynaptic transmission between mouse hippocampal neurones. J Physiol (Lond) 429:1-16.

Giniatullin RA, Khazipov RN, Vyskocil F (1993) A correlation between quantal content and decay time of endplate currents in frog muscles with intact cholinesterase. J Physiol (Lond) 466:95-103.

Harrison NL (1990) On the presynaptic action of baclofen al inhibitory synapses between cultured rat hippocampal neurones. J Physiol (Lond) 422:433-446.

Hartzell HC, Kuffler SW, Yoshikami D (1975) Post-synaptic potentiation: interaction between quanta of acetylcholine at the skeletal neuromuscular synapse. J Physiol (Lond) 251:427-463.

Hestrin S (1992) Activation and desensitization of glutamate-activated channels mediating fast excitatory synaptic currents in the visual cortex. Neuron 9:991-999.

Hestrin S (1993) Different glutamate receptor channels mediate fast excitatory synaptic currents in inhibitory and excitatory cortical neurons. Ncuron 11:1083-1091.

Hestrin S, Nicoll RA, Perkel DJ, Sah P (1990a) Analysis of excitatory synaptic action in pyramidal cells using whole-cell recording from rat hippocampal slices. J Physiol (Lond) 422:203-225.

Hestrin S, Sah P, Nicoll RA (1990b) Mechanisms generating the time course of dual component excitatory synaptic currents recorded in hippocampal slices. Neuron 5:247-253.

Isaacson JS, Nicoll RA (1991) Aniracetam reduces glutamate receptor desensitization and slows the decay of fast excitatory synaptic currents in the hippocampus. Proc Natl Acad Sci USA 88:10936-10940.

Isaacson JS, Nicoll RA (1993) The uptake inhibitor L-trans-PDC enhances responses to glutamate but fails to alter the kinetics of excit atory synaptic currents in the hippocampus. J Neurophysiol 70:21872191.

Isaacson JS, Solis JM, Nicoll RA (1993) Local and diffuse synaptic actions of GABA in the hippocampus. Neuron 10:165-175.

Jahr CE, Stevens CF (1993) Calcium permeability of the $N$-methyl-Daspartate receptor channel in hippocampal neurons in culture. Proc Natl Acad Sci USA 90:11573-11577.

Johnston D, Brown TH (1983) Interpretation of voltage-clamp measurements in hippocampal neurons. J Neurophysiol 50:464-486.

Jonas P, Major G, Sakmann B (1993) Quantal components of unitary EPSCs at the mossy fibre synapse on $\mathrm{CA} 3$ pyramidal cells of rat hippocampus. J Physiol (Lond) 472:615-663.

Katz B, Miledi R (1973) The binding of acetylcholine to receptors and its removal from the synaptic cleft. J Physiol (Lond) 231:549-574.
Katz B, Miledi R (1979) Estimates of quantal content during "chemical potentiation' of transmitter release. Proc R Soc Lond [Biol] 205:369378.

Kordas M (1972) An attempt at an analysis of the factors determining the time course of the end-plate current. I. The effects of prostigmine and of the ratio of $\mathrm{Mg}^{2+}$ to $\mathrm{Ca}^{2+}$. J Physiol (Lond) 224:317-332.

Korn H, Faber DS (1991) Quantal analysis and synaptic efficacy in the CNS. Trends Neurosci 14:439-445.

Korn H, Mallet A, Triller A, Faber DS (1982) Transmission at a central inhibitory synapse. II. Quantal description of release, with a physical corrclate for binomial n. J Ncurophysiol 48:679-707.

Lester RA, Clements JD, Westbrook GL, Jahr CE (1990) Channel kinetics determine the time course of NMDA receptor-mediated synaptic currents. Nature 346:565-567.

Livsey CT, Costa E, Vicini S (1993) Glutamate-activated currents in outside-out patches from spiny versus aspiny hilar neurons of rat hippocampal slices. J Neurosci 13:5324-5333.

Lupica CR, Proctor WR, Dunwiddie TV (1992) Presynaptic inhibition of excitatory synaptic transmission by adenosine in rat hippocampus: analysis of unitary EPSP variance measured by whole-cell recording. J Neurosci 12:3753-3764.

Magleby KL, Stevens CF (1972) The effect of voltage on the time course of end-plate currents. J Physiol (Lond) 223:151-171.

Magleby KL, Terrar DA (1975) Factors affecting the time course of decay of end-plate currents: a possible cooperative action of acetylcholine on receptors at the frog neuromuscular junction. J Physiol (Lond) 244:467-495.

Malgaroli A, Tsien RW (1992) Glutamate-induced long-term potentiation of the frequency of miniature synaptic currents in cultured hippocampal neurons. Nature 357:134-139.

Mallart A, Martin AR (1968) The relation between quantum content and facilitation at the neuromuscular junction of the frog. J Physiol (Lond) 196:593-604.

McNaughton BL (1980) Evidence for two physiologically distinct perforant path-ways to the fascia dentata. Brain Res 199:1-19.

Mennerick S, Zorumski CF (1994) Glial contributions to excitatory neurotransmission in cultured hippocampal cells. Nature 368:59-62.

Mennerick S, Que J, Benz A, Zorumski CF (1994) Passive and synaptic properties of neurons grown in microcultures and in mass cultures. J Neurophysiol, in press.

Patneau DK, Mayer ML (1990) Structure-activity relationships for amino acid transmitter candidates acting at $N$-methyl-D-aspartate and quisqualate receptors. J Neurosci 10:2385-2399.

Patıeau DK, Vyklicky L Ji, Mayer ML (1993) Hippocampal neurons exhibit cyclothiazide-sensitive rapidly desensitizing responses to kainate. J Neurosci 13:3496-3509.

Pearce RA (1993) Physiological evidence for two distinct $\mathrm{GABA}_{\mathrm{A}}$ responses in rat hippocampus. Neuron 10:189-200.

Pennefather P, Quastel DM (1981) Relation between subsynaptic receptor blockade and response to quantal transmitter at the mouse neuromuscular junction. J Gen Physiol 78:313-344.

Perkel DJ, Nicoll RA (1994) Evidence for all-or-none regulation of neurotransmitter release: implications for long-term potentiation. $\mathbf{J}$ Physiol (Lond) 471:481-500.

Sarantis M, Ballerini L, Miller B, Silver RA, Edwards M, Allwell D (1993) Glutamate uptake from the synaptic cleft does not shape the decay of the non-NMDA component of the synaptic current. Neuron 11:541-549.

Segal MM (1991) Epileptiform activity in microcultures containing one excitatory hippocampal neuron. J Neurophysiol 65:761-770.

Sheardown MJ, Nielsen EO, Hansen AJ, Jacobsen P, Honore T (1990) 2,3-Dihydroxy-6-nitro-7-sulfamoyl-benzo(F)quinoxaline: a neuroprotectant for cerebral ischemia. Science 247:571-574.

Sladeczek F, Pin JP, Recasens M, Bockaert J, Weiss S (1985) Glutamate stimulates inositol phosphate formation in striatal neurons. Nature 317:717-719.

Sorra KE, Harris KM (1993) Occurrence and three-dimensional structure of multiple synapses between individual radiatum axons and their target pyramidal cells in hippocampal area CA1. J Neurosci 13:37363748.

Spruston N, Jaffe DB, Johnston D (1994) Dendritic attenuation of synaptic potentials and currents: the role of passive membrane properties. Trends Neurosci 17:161-166.

Tarwana I, Farkas S, Bcrzsenyi P, Pataki A, Andrasi F (1989) Electro 
physiological studies with a 2,3 benzodiazepine muscle relaxant: GYKI 52466. Eur J Pharmacol 167:193-199.

Thio LL, Clifford DB, Zorumski CF (1991) Characterization of quisqualate receptor desensitization in cultured postnatal rat hippocampal neurons. J Neurosci 11:3430-3441.

Thio LL, Clark GD, Clifford DB, Zorumski CF (1992) Wheat germ agglutinin enhances EPSCs in cultured postnatal rat hippocampal neurons by blocking ionotropic quisqualate receptor desensitization. J Neurophysiol 68:1930-1938.

Thompson SM, Haas HL, Gahwiler BH (1992) Comparison of the actions of adenosine at pre- and postsynaptic receptors in the rat hippocampus in vitro. J Physiol (Lond) 451:347-363.

'long G, Jahr CE (1994) Multivesicular release from excitatory synapses of cultured hippocampal neurons. Neuron 12:51-59.

Trussell LO, Fischbach GD (1989) Glutamate receptor desensitization and its role in synaptic transmission. Neuron 3:209-218.

Trussell LO, Zhang S, Raman IM (1993) Desensitization of AMPA receptors upon multiquantal neurotransmitter release. Neuron 10 : $1185-1196$.

Vyklicky L Jr, Patneau DK, Mayer ML (1991) Modulation of excitatory synaptic transmission by drugs that reduce desensitization at AMPA/kainate receptors. Neuron 7:971-984.
Williams SH, Johnston D (1991) Kinetic properties of two anatomically distinct excitatory synapses in hippocampal CA3 pyramidal neurons. J Neurophysiol 66:1010-1020.

Wyllie DJ, Mathie A, Simonds CJ, Cull-Candy SG (1991) Activation of glutamate receptors and glutamate uptake in identified macroglial cells in rat cerebellar cultures. J Physiol (Lond) 432:235-258.

Yamada KA, Tang CM (1993) Benzothiadiazides inhibit rapid glutamate receptor desensitization and enhance glutamatergic synaptic currents. J Neurosci 13:3904-3915.

Yoon KW, Rothman SM (1991a) The modulation of rat hippocampal synaptic conductances by baclofen and gamma-aminobutyric acid. J Physiol (Lond) 442:377-390.

Yoon KW, Rothman SM (1991b) Adenosine intribits excitatory but not inhibitory synaptic transmission in the hippocampus. J Neurosci 11 : $1375-1380$.

Zengel JE, Magleby KL (1981) Changes in miniature endplate potential frequency during repetitive nerve stimulation in the presence of $\mathrm{Ca}^{2}, \mathrm{Ba}^{2+}, \mathrm{Sr}^{2+}$ at the frog neuromuscular junction. J Gen Physiol 77:503-529.

Zorumski CF, Yamada KA, Price MT, Ohney JW (1993) A benzodiazepine recognition site associated with the non-NMDA glutamate receptor. Neuron 10:61-67. 